\title{
A review of the phytochemical mediated synthesis of AgNP (silver nanoparticle): the wonder particle of the past decade
}

\author{
Wasim Akram Shaikh ${ }^{1}$ (D) Sukalyan Chakraborty ${ }^{1}$ (i) $\cdot$ Gary Owens $^{2}$ (D) $\cdot$ Rafique UI Islam $^{3}$ (i)
}

Received: 23 July 2021 / Accepted: 25 September 2021 / Published online: 30 October 2021

(c) King Abdulaziz City for Science and Technology 2021

\begin{abstract}
Silver nanoparticle (AgNP) has been one of the most commonly used nanoparticles since the past decade for a wide range of applications, including environmental, agricultural, and medical fields, due to their unique physicochemical properties and ease of synthesis. Though chemical and physical methods of fabricating AgNPs have been quite popular, they posed various environmental problems. As a result, the bioinspired route of AgNP synthesis emerged as the preferred pathway for synthesis. This review focuses extensively on the biosynthesis of AgNP-mediated through different plant species worldwide in the past 10 years. The most popularly utilized application areas have been highlighted with their in-depth mechanistic approach in this review, along with the discussion on the different phytochemicals playing an important role in the bio-reduction of silver ions. In addition to this, the environmental factors which govern their synthesis and stability have been reviewed. The paper systematically analyses the trend of research on AgNP biosynthesis throughout the world through bibliometric analysis. Apart from this, the feasibility analysis of the plant-mediated synthesis of nanoparticles and their applications have been intrigued considering the perspectives of engineering, economic, and environmental limitations. Thus, the review is not only a comprehensive summary of the achievements and current status of plant-mediated biosynthesis but also provides insight into emerging future research frontier.
\end{abstract}

Keywords Silver nanoparticle $\cdot$ Plant-mediated synthesis $\cdot$ Bibliometric analysis $\cdot$ Phytochemicals

\section{Introduction}

Sukalyan Chakraborty

su_kalyanc@yahoo.co.uk;

sukalyanchakraborty@bitmesra.ac.in

Wasim Akram Shaikh

wasim.bu12@gmail.com

Gary Owens

gary.owens@unisa.edu.au

Rafique Ul Islam

rafique@mgcub.ac.in

1 Environmental Engineering Laboratory, Department of Civil and Environmental Engineering, Birla Institute of Technology, Ranchi, Mesra, Jharkhand 835215, India

2 Environmental Contaminants Group, Future Industries Institute, University of South Australia, Mawson Lakes Campus, Adelaide 5095, Australia

3 Department of Chemistry, School of Physical and Material Sciences, Mahatma Gandhi Central University, East Champaran, Motihari, Bihar 845401, India
Nanotechnology is a new branch of colloidal science that has gained immense importance over the past decade (Mondal et al. 2021). Nanotechnology is concerned with the study of materials at the nanoscale where the fundamental structural units of this novel technology are nanoparticles (NPs) which have sizes ranging from 1 to $100 \mathrm{~nm}$ in at least one dimension (Ajitha et al. 2015; Mondal et al. 2019; Kumar et al. 2021b). Many different types of NPs have been synthesized, modified and applied constructively in a wide variety of disparate fields including drug delivery, environmental remediation, material engineering food industries, and medicine (Shaikh et al. 2020). In some fields, advancements have been remarkable, incluing the use of semiconductor NPs for water splitting (Hisatomi et al. 2014), various environmental applications (Mondal et al. 2021), medical application (Gujrati et al. 2014), and application in electronic fild like sensor (Ahmad et al. 2011). Amongst the metallic NPs, silver nanoparticles (AgNPs) have been applied most beneficially across a variety of diverse application 
fields due to their unique biological, chemical, and physical properties including excellent catalytic activity, chemical stability, high electrical conductivity, optical and thermal properties (Shaikh et al. 2018). Consequently, amongst the metallic NPs, AgNPs have become one of the most significant nanomaterials attracting tremendous research interest. Thus, AgNPs have been successfully used in various fields, including antibacterial, antifungal, antiviral, anti-inflammatory activities, composite fibers, cryogenic superconducting materials, electronic component, food industry, health care, industrial purposes, medical, photocatalytic degradation of dye and can also be easily assimilated into cosmetic products (Ajitha et al. 2014b; Shaikh et al. 2018, 2020; Mondal et al. 2019, 2021). In addition, due to the presence of Surface Plasmon Resonance (SPR) phenomenon, AgNPs have attracted unparalleled attention as color-based biosensors (Ahmed et al. 2016).

Initially research focused on the development of robust methods for AgNP synthesis. Today a wide variety of synthetic methods have been established including chemical methods (Iravani and Zolfaghari 2013), electrochemical (Lim et al. 2006), microwave-assisted synthesis (Darmanin et al. 2012), photochemical reductions (Remita et al. 2007) and physical synthesis (Ashkarran 2010). All of these methods have their specific own limitations, such as the use of toxic chemicals as reducing and/or stabilizing agent, the requirement for high vacuum technology or other expensive equipment, production of impure AgNPs of very low yield, and high operating costs (Shaikh et al. 2018). For these reasons there is still a need to develop alternative synthetic routes for AgNP.

A holistic view of the current emerging trends in AgNP synthesis was identified through an open-access database search engine (dimensions), and VOSviewer software in the present review. In the past decade, biological routes for AgNP synthesis have become increasingly popular due to the advantages of providing a one-step synthesis of nontoxic, eco-friendly NPs without the need for preservation or additional maintenance of cultures (Shaikh et al. 2020). Till date, numerous plant species have been utilized for the biosynthesis of AgNP worldwide. Hence this review attempts to summarize the wide variety of plant species and their biochemicals, responsible for the synthesis of AgNP and critically evaluates their limitations and feasibility for real applications.

\section{Applications of biosynthesized AgNP}

\section{Antibacterial activity of AgNP}

Silver nanoparticles have been extensively used in food storage, the health industry, as textile coatings, and in some environmental applications as an antibacterial agent. Several accredited bodies including the US EPA, US FDA, SIAA of Japan, Korea's Testing and many research institutes have approved products containg AgNP within certain ranges for food storage, health industry, and textile coatings (Gupta et al. 2018). The antibacterial properties exhibited by AgNP tend to depend on several parameters such as shape, size, $\mathrm{pH}$, temperature and most importantly the capping agent used (Ahmed et al. 2016; Edhari et al. 2021). The antibacterial properties of biologically synthesized AgNP were investigated by several methods including the following: the disk diffusion method (Jyoti et al. 2016), the Agar well diffusion assay (Nayak et al. 2015), Kirby-Bauer (Mariselvam et al. 2014) and standard plate count (Zhang et al. 2014).

Several pathogenic Gram (-)ve bacteria such as Pseudomonas aeruginosa, Escherichia coli, Klebsiella pneumonia, and Gram (+) ve like Staphylococcus aureus, Bacillus pumilis, Bacillus subtilis, Streptococcus pyogenes were tested to investigate their antimicrobial activity (Table S1) (Rao et al. 2016). Results indicated a concentration-dependent inhibition of bacterial growth for B. subtilis and $E$. coli, with a Minimum Inhibitory Concentrations (MIC) of 6.25-12.5 and 12.5-25 $\mu \mathrm{g} \mathrm{mL}^{-1}$, and where no growth was observed in plates above 12.5 and $25 \mu \mathrm{g} \mathrm{mL}^{-1}$, respectively (Rao et al. 2016). Similarly, the MIC for some several other bacterial strains like Plesiomonas shigelloides, Bacillus subtilis, Pseudomonas aeruginosa, Vibrio alginolyticus, and Klebsiella pneumonia were routinely found to be at AgNP doses $<15 \mu \mathrm{g} \mathrm{mL} \mathrm{m}^{-1}$ (Okafor et al. 2013).

\section{Mechanism of antibacterial activity of biosynthesized AgNP}

The exact mechanism of interaction between AgNP and the constituents of the outer membrane of $E$. coli is only partially known. However, since E. coli cells are made up of soft bases like phosphorus and sulfur, acid-base reactions between the metallic nanoparticles and the microbial cells are believed to lead to cell death (Prabhu and Poulose 2012). Since basic sulfur and phosphorus are major components of DNA and AgNP interacts with such soft bases (Hatchett and White 1996), exposure to AgNP may stop DNA replication, resulting in protein formation inhibition (Feng et al. 2000). Betina (1966) showed after treatment with AgNP the protein (DNA and/or ribosomal protein) became denatured due to the formation of a bond between $\mathrm{Ag}^{+}$and the proteins functional groups. Some researchers claim that the antibacterial properties of $\mathrm{AgNP}$ were due to electrostatic attraction between positively charged nanoparticles and negatively charged bacterial cells (Stoimenov et al. 2002). It is assumed that the cell wall degrades when AgNP interacts with binding biomolecules of the cell wall which finally causes cell death (Stoimenov et al. 2002). 
Another probable mechanism often proposed following AgNP exposure is that cell death around the wall occurs due to disorganization of cytoplasmic membrane and linkages of several biomolecules like carbohydrates, amino acids, and protein (Patil et al. 2012). It is well known that AgNPs can form complexes with nucleic acids via interaction with the nucleosides groups of nucleic acids which results in antimicrobial activity (Ahmed et al. 2016).

\section{Degradation of toxic dyes using AgNPs}

The number of commercially available dyes is currently estimated to exceed 1 million, where at least 10,000 difffert dyes are routinely used in the cosmetic, dyeing, leather, paper, pharmaceutical plastic, printing and textile industries (Shaikh et al. 2021). As a result, about 0.7 million tons of dye wastes are commonly released in effluent annually (Shaikh et al. 2020), where non-biodegradable bi-products (dyes and dyestuff) pose major environmental threats to the biosphere. This is one of the most alarming environmental problems, where AgNP particles have exhibited considerable mitigation options (Ghazal et al. 2020). This is an area where the role of AgNP for the degradation of toxic industrial dyes from wastewater by either catalytic or photocatalytic degradation has received much attention (Table 1).

\section{Catalytic degradation}

Relative to equivalent bulk materials of the same mass, AgNPs show improved catalytic activities due to a relatively greater surface area with a lower volume. Normally, the large difference in redox potential between the electron donor and the electron accepter makes reaction difficult by limiting electron transfer between acceptor and donor due to the limited passage of electrons (Tripathi et al. 2013). However, for AgNPs in presence of borohydride ion, an electron donor helps to cross the activation energy barrier in the catalytic degradation reaction (Varadavenkatesan et al. 2019).

\section{Mechanism of catalytic dye degradation using AgNPs}

The Bond Dissociation Energy (BDE) plays a significant role in most chemical reactions because it is often necessary to break exisiting bonds to form new ones. In a typical degradation system, $\mathrm{NaBH}_{4}$ acts as an eletron donor and releases electrons to the dye, which acts as an eletron acceptor and receives the electron (Varadavenkatesan et al. 2019). When $\mathrm{AgNP}$ is present in this sytem, it acts as a catalyst by helping the "electron-shuttling" process, more efficiently passing electrons to the acceptor (dyes) from the donor $\left(\mathrm{NaBH}_{4}\right)$ but via AgNP. This electron relay process causes surface alteration of AgNPs which visually appears as blue spectral shift of the surface plasmon resonance band of AgNPs (Pradhan et al. 2002). The spectral blue shift results in the resonance band of AgNP overlapping the absorption peak of the dye (corresponds to $n-\pi^{*}$ and/or $\pi-\pi^{*}$ transitions of dye) (Varadavenkatesan et al. 2019). Thus, electron transfer becomes easier and smoother when a catalyst has an intermediate redox potential between that of the acceptor and the donor (Tripathi et al. 2013). This is shown visually in Fig. 1.

\section{Photocatalytic dye degradation}

Biosynthesized AgNPs are often very effective photo-catalytic degraders of toxic dyes due to surface plasmon resonance (SPR) where photocatalytic degradation efficiency increases as the metal nanoparticle size decreases (Table 1). Photocatalysis is the mutual competition between separation and recombination of electron-hole pairs [valence band (VB) and conduction band (CB)]. Photocatalytic activity was generally increased by increasing the number of electron-hole pairs on the surface of the charge carrier. During photocatalytic degradation, when light photons hit the valence electrons of AgNPs, they gained energy and thereafter the valence shell emitted highly energetic electrons, which generated active radicles which acted as potent oxidizing agent to completely degrade dye to non-hazardous products like $\mathrm{CO}_{2}, \mathrm{H}_{2} \mathrm{O}, \mathrm{NH}_{4}{ }^{+}$, and $\mathrm{NO}_{3}{ }^{-}$(Shaikh et al. 2018, 2020).

\section{Mechanism of photo-catalytic dye degradation using AgNPs}

Under visible and/or UV irradiation the VB electrons of the metal are excited and promoted to the $\mathrm{CB}$, creating conduction electron $\left(\mathrm{e}^{-}{ }_{\mathrm{CB}}\right)$ in the $\mathrm{CB}$ and a positive hole $\left(\mathrm{h}^{+}{ }_{\mathrm{VB}}\right)$ in the VB (Eq. 1) (Sinha et al. 2014) (Fig. 2). These photogenerated species $\left(\mathrm{h}^{+}{ }_{\mathrm{VB}}\right.$ and $\left.\mathrm{e}_{\mathrm{CB}}^{-}\right)$generate highly reactive radicals capable of dye degradation (Shaikh et al. 2018). For example, $\mathrm{h}^{+}{ }_{\mathrm{VB}}$ can dissociate water $\left(\mathrm{H}_{2} \mathrm{O}\right)$ into hydrogen $\left(\mathrm{H}^{+}\right)$and hydroxyl $\left({ }^{-} \mathrm{OH}\right)$ ion, where the hydroxyl $\left({ }^{-} \mathrm{OH}\right)$ ion is subsequently convertedinto a hydroxyl radical $(\cdot \mathrm{OH})$ (Eq. 2 and 3). Simultaneously, $\mathrm{e}_{\mathrm{CB}}^{-}$can convert dissolved oxygen $\left(\mathrm{O}_{2}\right)$ into a superoxide radical anion $\left(\cdot \mathrm{O}_{2}^{-}\right)$(Eq. 4) (Saravanakumar et al. 2016), which can therafter also react with $\mathrm{H}_{2} \mathrm{O}$ to produce both $\cdot \mathrm{OH}$ and the hydroperoxyl radical $\left(\mathrm{HO}_{2}{ }^{\circ}\right.$ ) (Eq. 5) (Shaikh et al. 2020). These three photogenerated radicals $\left(\cdot \mathrm{OH}, \cdot \mathrm{O}_{2}^{-}\right.$, and $\left.\mathrm{HO}_{2} \cdot{ }^{\cdot}\right)$ all contribute to the degradation of complex dyes into simple non-toxic fragments like ammonium $\left(\mathrm{NH}_{4}^{+}\right)$, carbon dioxide $\left(\mathrm{CO}_{2}\right)$, nitrate $\left(\mathrm{NO}_{3}{ }^{-}\right)$, and water $\left(\mathrm{H}_{2} \mathrm{O}\right)$ (Eq. 6) (Tahir et al. 2015).

$\operatorname{AgNP}+\mathrm{h} \nu(\lambda<390 \mathrm{~nm})=\operatorname{AgNP}\left(\mathrm{h}^{+}\right)+\operatorname{AgNP}\left(\mathrm{e}^{-}\right)$,

$\operatorname{AgNP}\left(\mathrm{h}^{+}\right)+\mathrm{H}_{2} \mathrm{O}=\mathrm{H}^{+}+-\mathrm{OH}$, 


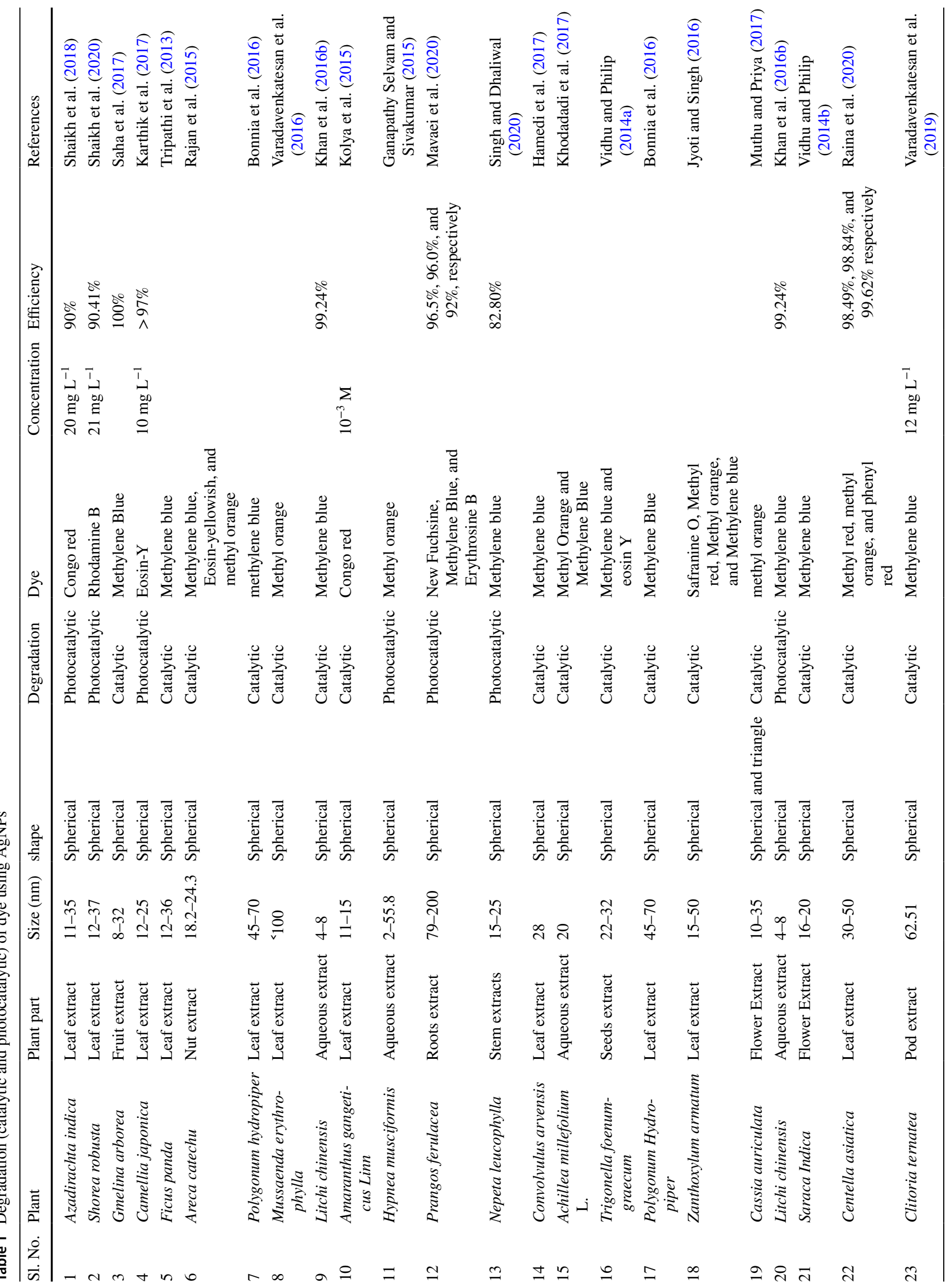




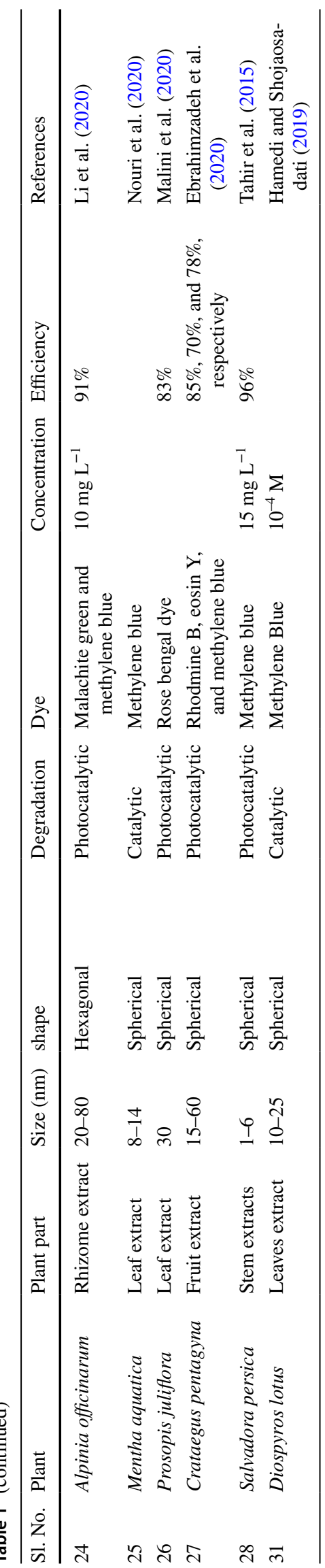

$\operatorname{AgNP}\left(\mathrm{h}^{+}\right)+{ }^{-} \mathrm{OH}+\mathrm{H}^{+}=\operatorname{AgNP}(\cdot \mathrm{OH})+\mathrm{H}^{+}$,

$\operatorname{AgNP}\left(\mathrm{e}^{-}\right)+\mathrm{O}_{2}=\operatorname{AgNP}\left(\cdot \mathrm{O}_{2}^{-}\right)+\mathrm{H}^{+}$,

$\operatorname{AgNP}\left(\cdot \mathrm{O}_{2}^{-}\right)+\mathrm{H}_{2} \mathrm{O}=\operatorname{AgNP}(\cdot \mathrm{OH})+\operatorname{AgNP}\left(\mathrm{HO}_{2} \cdot\right)$,

Dyes $+\operatorname{AgNP}\left(\cdot \mathrm{O}_{2}^{-}\right) / \operatorname{AgNP}(\cdot \mathrm{OH}) / \operatorname{AgNP}\left(\mathrm{HO}_{2} \cdot\right)$

$=$ Fragmented products.

\section{Biosensing}

Due to the surface plasmon resonance (SPR) effect and changes induced in nanoparticles' shape and size, triangular AgNPs have recently attracted tremendous attention as a color based biosensor. These AgNP-based nanosensors have two unique characteristics: (i) unique refractive sensitivity and (ii) short-range sensing by the local electromagnetic field, where the combined contributuion of these two properties results in sensitivity of $\sim 100-1000 \mathrm{pg} \mathrm{mm}^{-2}$ (Larguinho and Baptista 2012). Bindhu and Umadevi (2014) reported biosynthesis of AgNPs using Solanum lycopersicums extract and successfully applied it for the sensing of heavy metal ions $\left(\mathrm{Fe}^{3+}\right.$ and $\left.\mathrm{Cu}^{2+}\right)$ in water by using a SPR optical sensor. Kirubaharan et al. (2012) prepared AgNPs using an Azadirachta indica extract, where the biosynthesized AgNPs exhibited excellent specific metal $\left(\mathrm{Cu}^{2+}\right)$ ion selectivity. This study also showed significant $\mathrm{Cu}^{2+}$ selectivity even when $\mathrm{Cu}$ was present in minimal concentration $\left(0.001 \mathrm{mg} \mathrm{L}^{-1}\right)$ in aqueous solution. AgNPs have also been considered in bio-molecular diagnostics, including for biomarker characterization and detection of gene expression profiles, characterization of proteins, DNA or RNA, and nucleic acids (Goyal et al. 2009).

\section{Biomedical applications of AgNPs}

Increasingly, a range of metal nanoparticles, but especially AgNP, have played important roles in the recent development of science and technology (Shamaila et al. 2016). In the past decade, AgNP has attracted tremendous attention in the medical field for precise and selective drug-delivery resulting in enhanced pharmacokinetics, pharmacodynamics, and a high capacity to bind with a wide range of biomolecules (Burdușel et al. 2018). Such specific drugdelivery system has proved extremely useful in providing suitable drug release profiles with maximum therapeutic efficiency and minimal side-effects. Recent improvements of AgNPs via surface modification have also led to 
Fig. 1 Mechanism of catalytic dye degradation using AgNP

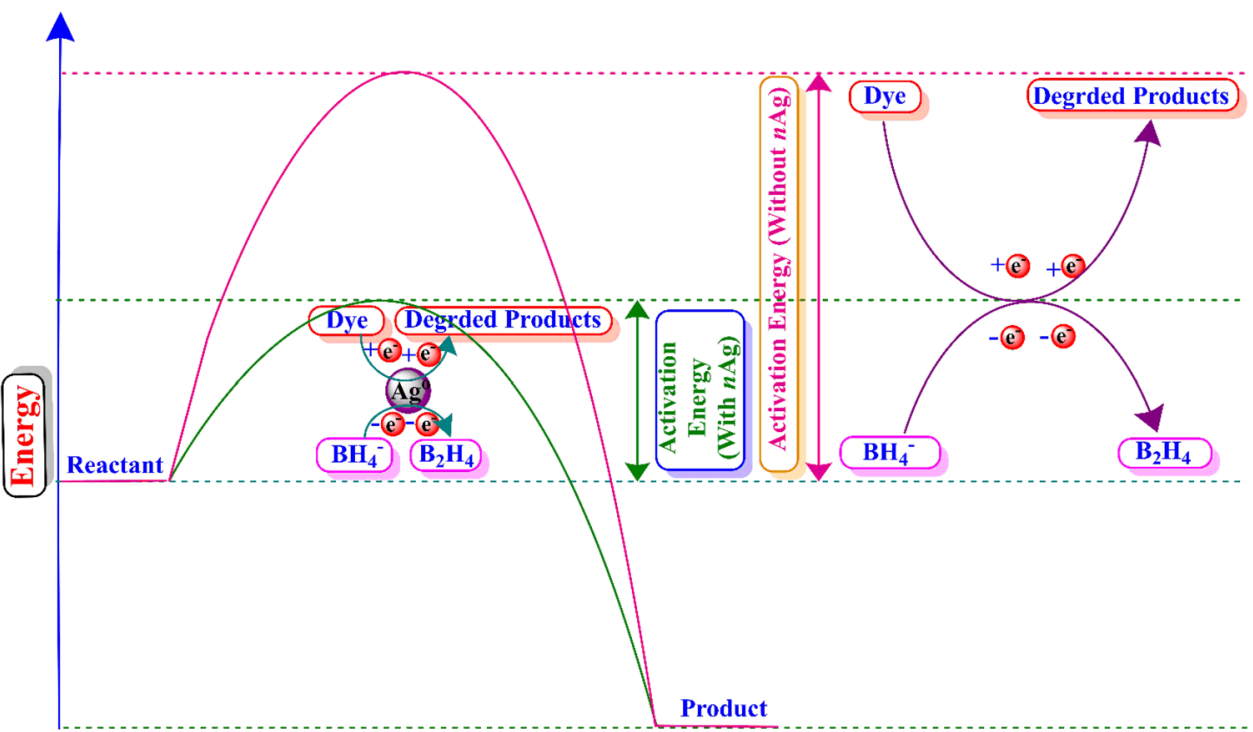

Fig. 2 Mechanism of photocatalytic degradation of dyes using AgNP

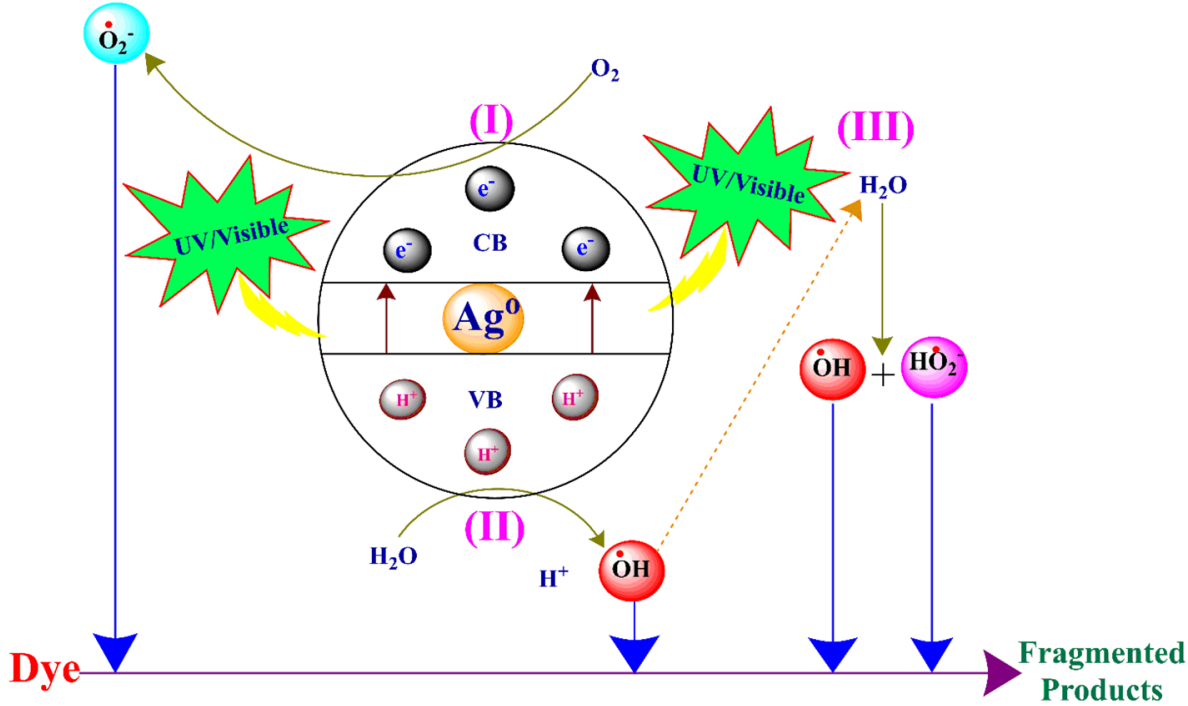

enhanced biocompatibility and stability, which has only enhanced AgNP suitability as a nanoscale drug-delivery system. Indeed, the unique target specificityof AgNP have resulted in its extensive use in nanoparticle-based drugdelivery applications, specifically anti-cancer and anti-tumor drug delivery systems (Philip et al. 2011).

In addition, AgNP has also proven to be a potent antimicrobial and antipathogenic agent, in dental-related nanotechnology-based strategies (Qing et al. 2018). The main aim of using AgNP in dentistry has been to protect against harmful pathogens and protect the oral cavity (Burdușel et al. 2018). For example, the good biocompatability of AgNP was shown to be useful as a coating material for dental barrier membranes (DBM). Such AgNP coatings have also been shown to prevent pathogenic contamination from dental implants' and poor tooth-brushing techniques. Recently, AgNP has also been used in tooth stainers in the form of nanosilver diamine fluoride (SDF); however, the effect of this new compound is still unknown (Burdușel et al. 2018). Moreover, Qing et al. (2018) reported AgNP as a coating material (silver-coated prostheses) for an unconventional approach for prophylaxis of tumor-related infections in the Orthopedic and bone-implant-related field.

\section{Use of AgNP for COVID-19 mitigation}

Currently the COVID-19 pandemic is a major urgent topic of scientific endeavour. The current pandemic, coronavirus disease (COVID-19), has spread almost all over the world (over 221 countries), with $>138,057,338$ infected people causing the death of $>2,972,992$ people. Scientists around the world have done significant studies to develop 
therapeutics or vaccines. However, the efficiency of these vaccines is still questionable. A considerable effort has also been given to nano-based anti-viral agents or vaccines, all of which are currently in initial development phases far from public implementation. However, Talebian et al. (2020) proposed metallic nanoparticles $\left(\mathrm{Ag}, \mathrm{Cu}, \mathrm{TiO}_{2}\right)$ as an alternative to conventional approaches to fighting COVID-19. Among these various nanoparticles, AgNP has already shown significant promising results as a durable and self-sterilizing agent. Talebian et al. (2020) reported AgNP has been used as a photocatalytic coating agent on the surface of COVID19 test kits and the coating layer of respiratory face masks. AgNP-based fortification equipment and disinfecting agents can provide enhanced protection against SARS-CoV-2 and carrier for antigens or as an adjuvant, making way to develop new generation of vaccines (Rai et al. 2021). However, the main disadvantages with these kits where the chance of false-negative results, poor analytical sensitivity, long response time, and the health impact of the AgNP coated kit on a human are yet to be studied (Vaculovicova et al. 2017). To overcome these challenges, recently, Swiss researchers developed a dual-functional plasmonic biosensor (involving a combination of a localized surface plasmon and photothermal resonance plasmon), as a promising alternative to $\mathrm{AgNP}$ for clinical diagnosis of COVID-19 (Qiu et al. 2020).

\section{Approaches of silver nanoparticle synthesis}

There are two main approaches involved in AgNP synthesis, 'bottom up' or 'top down' (Ahmed et al. 2016). In the topdown approach, nano-sized particles are synthesized from a suitable bulk material by breaking down the parent material via size reduction (Fig. 3). The most common methods employed in the top-down approach include chemical etching, combustion, mechanical/ball milling, sputtering, and thermal/laser ablation (Mittal et al. 2013). The key step in all these methods is the reduction or breakdown of the parent starting material. However, one major limitation of these processes is that they result in AgNPs which have significant surface imperfections due to the alteration of the physical and chemical properties of the starting material (Mittal et al. 2013).

In the "bottom up" approach, a range of mainly physiochemical, and occasionaly biological methods are used in the self-assembly of atoms to develop new nuclei of a particular nanosize. Common bottom-up approaches include aerosol process, atomic/molecular condensation, (electro)chemical precipitation, laser pyrolysis, sol-gel process, spray pyrolysis, vapor deposition and bio-reduction (Mittal et al. 2013).

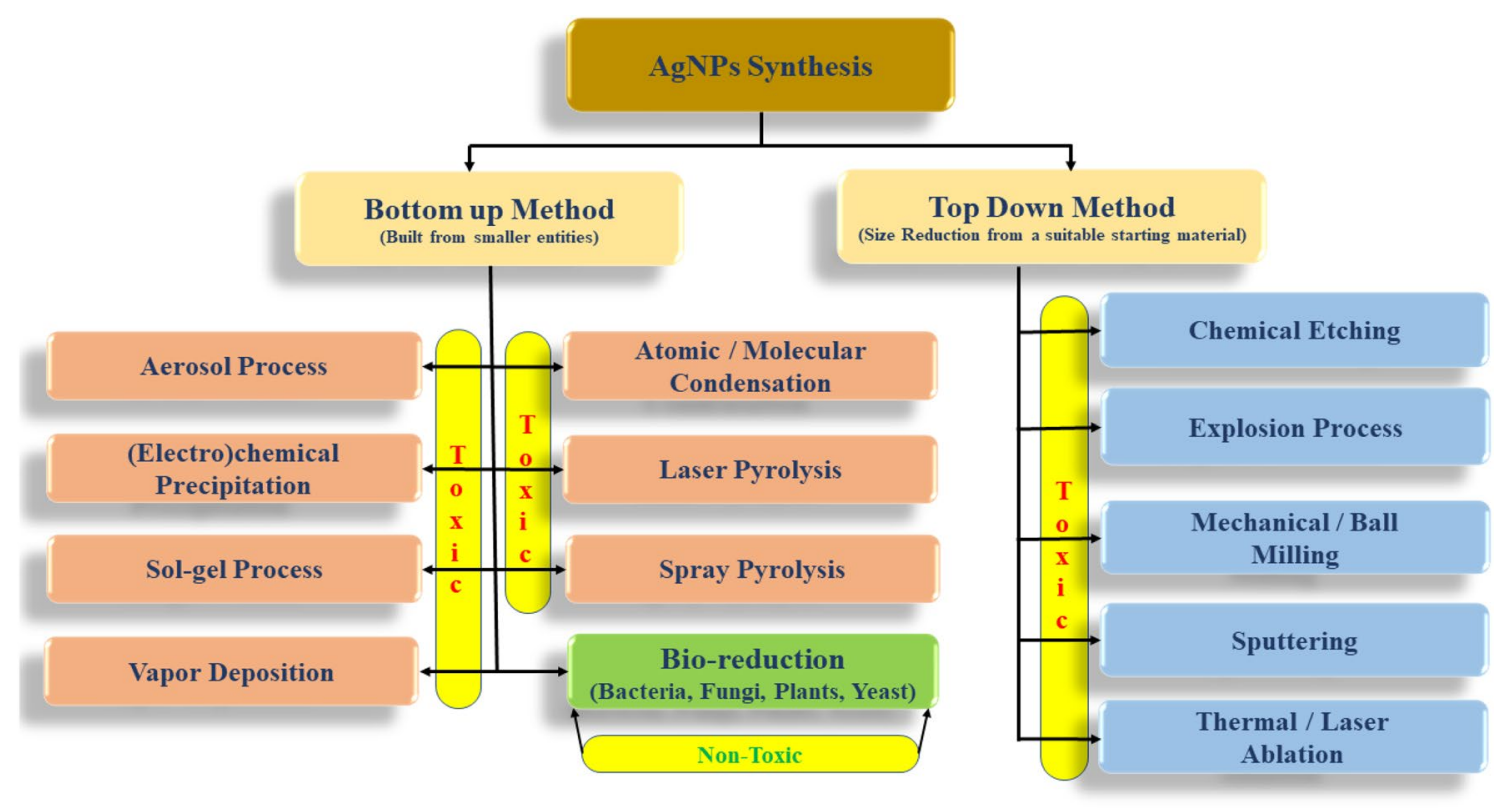

Fig. 3 Different approaches for silver nanoparticles synthesis 


\section{Conventional methods adopted for the biosynthesis of AgNP}

Biosynthesis of AgNP mainly involves the following three common steps: 1 . collection, 2. Extraction, and 3. reaction, which are briefly described as follows:

i. Collection and preparation: The first step involves the collection and segregation of the target plant species. The target plant part is then washed with tap water twice or thrice and finally with distilled water to remove any impurities, debris or organic substances adhering to the materials.

ii. Then the fresh uncontaminated plant parts are either shade-dried for 10-15 days till constant weight and finally powdered with a grinder, or blotted dry, cut into pieces, and boiled with millipore water for $30 \mathrm{~min}$ to prepare the plant extract (Joseph and Mathew 2015). Another extraction method invlolves grinding the fresh plant part after thorough washing with millipore water and/or ethanol. The extract is finally filtered using Whatman filter paper no. 1 and stored at $4{ }^{\circ} \mathrm{C}$ for further use (Shaikh et al. 2018, 2020; Mondal et al. 2021).

iii. Reaction: The last step of the biosynthesis process is the reduction process where the plant extract is added to $1-10 \mathrm{mM} \mathrm{AgNO}_{3}$ to reduce the pure $\mathrm{Ag}(\mathrm{I})$ ions to $\operatorname{Ag}(0)$ at room temperature normally in a reaction lasting upto $6 \mathrm{~h}$. Typically, the bio-reduction process is monitored by measuring the UV-visible spectrum at 200-800 $\mathrm{nm}$ with a regular interval of $0.5 \mathrm{~nm}$, where the AgNP peak arises around 400-450 nm (Mondal et al. 2019, 2021; Shaikh et al. 2020).

\section{Disadvantages of conventional synthesis methods}

While the physiochemical route of AgNP synthesis is useful for large-scale production of high-purity AgNPs with superior physical properties, the top down method does have several disadvantages including the following:

i. Most physical methods need expensive equipment and high vacuum technology.

ii. Mechanical/ball milling methods often require substantial amounts of the initial bulk material, which must be subjected to high mechanical energy over an extended period, which tends to result in a high probability of some surface deterioration and contamination due to the use of steel grinding balls.

iii. During ion sputtering methods, the process of vaporizing solid materials and sputtering through inert gas ion beams of $\mathrm{He}, \mathrm{Ne}, \mathrm{Ar}, \mathrm{Kr}$, or $\mathrm{Xe}$, can influence the final composition, optical properties, surface morphology, and texture of the nanoparticle produced.

iv. While applying the laser ablation method, where NPs are synthesized by reduction of size using laser irradiation, the main disadvantage is the low yield due to blockage of the laser path and energy in the colloidal solution (Jamkhande et al. 2019).

Likewise, the bottom up methods also have a range of distinct disadvantages. For example:

i. Chemical methods need a range of different, often toxic inorganic and/or organic reducing agents, to act as both reducing and, to prevent agglomeration, capping agents This can include ascorbate, elemental hydrogen $(\mathrm{H})$, sodium citrate $\left(\mathrm{Na}_{3} \mathrm{C}_{6} \mathrm{H}_{5} \mathrm{O}_{7}\right)$, sodium borohydride $\left(\mathrm{NaBH}_{4}\right)$, Tollen's reagent $\left[\mathrm{Ag}\left(\mathrm{NH}_{3}\right)_{2}\right]$ $\mathrm{NO}_{3}$ and $N, N$-dimethyl formamide $\left(\mathrm{C}_{3} \mathrm{H}_{7} \mathrm{NO}\right)$ in both polar or non-polar solvents (Ajitha et al. 2014a).

ii. Reducing chemicals are often toxic, relatively expensive and can create impurities in the final NPs, which can become secondary pollutants when practically applied.

iii. Bottom-up methods tend to be relatively expensive, low yield methods, difficult to control leading to low reproducibility (Jamkhande et al. 2019).

To address these major concerns, currently the main focus of AgNP synthesis research has been the synthesis of nontoxic and environment friendly AgNP through biological pathways (Ahmad et al. 2010). This is because biosynthesized AgNP is generally identified as non-toxic with less environmental impacts than other physiochemical methods (Ahmed et al. 2016). Unlike traditional chemical methods, the biosynthesis approach has the advantage of using a single aqueous plant part extract, as both the reducing as well as stabilizing agent rather than a suite of toxic chemicals. While this is a single natural extract, several biomolecules may be involved as either reducing and/or capping biomolecules (Shaikh et al. 2018, 2020). The other main advantage of biosynthesis of AgNPs is that they generally yield large amounts of AgNPs with well-defined size and morphology (Hutchison 2008).

\section{Biosynthesis of AgNP}

Although the mechanism was not well understood, the reduction of metal ions by plant extracts was first identified in the early 1900s (Mittal et al. 2013). Since then, a range of metals have been sucessfuly reduced via a range of 
plant materials. However, in the last 35 years, bio-synthesis of AgNP has attracted significant attention using either extracts of plant tissue, plant parts or indeed the whole plant (Fatimah 2016). The bio-reduction process simply involves mixing of a metal solution with plant extracts at room temperature (Mittal et al. 2013). The main objectives during the green synthesis of AgNP is to maximize safety and efficiency and minimize the environmental and societal impact of toxic raw materials. The nature, yield, quality, and characteristics of the produced AgNP are influenced mainly by the relative concentrations of plant extract and metal salt, contact time, temperature, and reaction $\mathrm{pH}$ (Dwivedi and Gopal 2010).

The choice of plant extract may also be important because several plants and their respective parts may contain different biomolecules which can act as reducing agent as well as stabilizing agents during bio-reduction (Table 2). These biomolecules may also influence the overall surface characteristics of the AgNPs and also agglomeration in solution due to the numerous possible combinations of biomolecule interactions with the AgNPs (Mittal et al. 2013). Thus, the various different plant types and parts currently used for the biosynthesis of AgNP is briefly discussed below.

\section{Biosynthesis of AgNP using leaf, root, shoot, flower, and fruit extract}

The successful synthesis of AgNP using different plant parts has been summarized in Table 2. Generaly most of the AgNP particles synthesized with various plant parts yielded spherical AgNPs with an average size of 5 to $85 \mathrm{~nm}$ (Mittal et al. 2013). However, non-spherical AgNPs, i.e. triangular, pentagonal, and hexagonal, were also reported using Eclipta prostrate leaf extract; where the particle size ranged between 30 and $60 \mathrm{~nm}$ when the reaction occurred at room temperature (Rajakumar and Abdul Rahuman 2011). Similarly, both cubic and irregular AgNPs were also synthesized using the seeds of Trachyspermum ammi and Artocarpus heterophyllus, respectively (Jagtap and Bapat 2013). At room emperature biosynthesis reaction times ranged between 10 and $300 \mathrm{~min}$. The bio-reduction of the Ag precursor was ascribed to high levels of biomolecules in the different plant parts (leaves, fruits, flowers, seeds, barks and roots). These biomoluces could be very diverse and include a myriad of alcohols, alcoholic compounds, alkaloids, alkynes, allylic benzenes, amide, amino acids, amino acid residues, anthraquinones, ascorbic acid, benzoates, caffeoyl, carbohydrates, carotenes, catechic tannins, diterpenoids, flavonoids, glycosides, iridoids, leucocyanidin, proteins, phenols, phenolic compounds, saponins, steroids, sugars, tannins, terpenoids, triterpenoids, traces of reducing sugars, triterpenes, and vitamin C) which acted both as reducing and/or capping or stabilizing agents (Ebrahimzadeh et al. 2020). Though the phytochemicals present in the different plant extracts have been identified by several researchers, no one was able to clearly identify one specific biomolecule involved in the bio-reduction of $\mathrm{Ag}^{+}$to AgNP. Biosynthesized AgNP, using various leaf extracts, has generally shown several important properties including excellent antibacterial activities, cytotoxic, mosquitocidal activity, synergistic effects with antibiotics, anticancer effects against human breast cancer cells (MCF-7), and photocatalytic degradation of dye (Shaikh et al. 2020). AgNP synthesized from flower extracts was also shown to have efficient catalytic activity for the reduction of cationic dyes such as methylene blue in the presence of $\mathrm{NaBH}_{4}$ by generating active free radicals $\left(\cdot \mathrm{OH}, \cdot \mathrm{O}_{2}^{-}\right.$and $\mathrm{HO}_{2} \cdot$ ) and antibacterial efficiency due to deterioration of the plasma membrane by AgNP penetration through the cell wall causing bacterial cell death in cytotoxic studies using human cell lines (Ocsoy et al. 2017). Fruit extract (Lycium barbarum) mediated AgNP also exhibited good optical properties suitable for uses as sensors (Saha et al. 2017).

While Ameen et al. (2019) reported the successful biosynthesis of AgNP using a Mangifera indica flower extract, no identification of the specific phytochemicals responsible for reduction was provided. However, other researchers like Hamedi and Shojaosadati (2019) did include a general screening and characterization of the phytochemicals responsible for AgNP synthesis when using a Diospyros lotus extract, which showed that alkaloids, anthraquinones, flavonoids, saponins, steroids, tannins, and terpenoids were all key components. In fact, of the more than 200 plant species from 86 families extracted and used for AgNP synthesis, most studies have conclusivley identified as the specific phytochemical(s) involved, creating a huge knowledge gap regarding the specific phytochemical(s) responsible for either reduction and/or capping during AgNP biosynthesis and the underlying reaction mechanisms. Some attempts to explore the mechanisms by FTIR techniques implicate amide, carboxylate, carbonyl group, proteins, terpenoids, ketones, and aldehydes of Vigna sp. seed extract (Mohammadi et al. 2016), but ideifiication of specific biochemicals is a challange.

\section{Bio synthesis using other plant parts}

Rapid green synthesis of AgNP has also been reported by some other plant parts including pericarp extracts of Sapindus emarginatus (Swarnavalli et al. 2017), Allium stipitatum (shallot) (Taheri et al. 2015), and apricot tree gum (Rajkuberan et al. 2017), latex extract of Euphorbia antiquorum L., (Mariselvam et al. 2014) inflorescence of Cocos nucifera (Edison and Sethuraman 2012), and Musa sp. (Banana) peel extract (Ibrahim 2015). As with most other plant extract derived NPs most of the biosynthesized AgNP were spherical having a particle size ranging between 4 and 


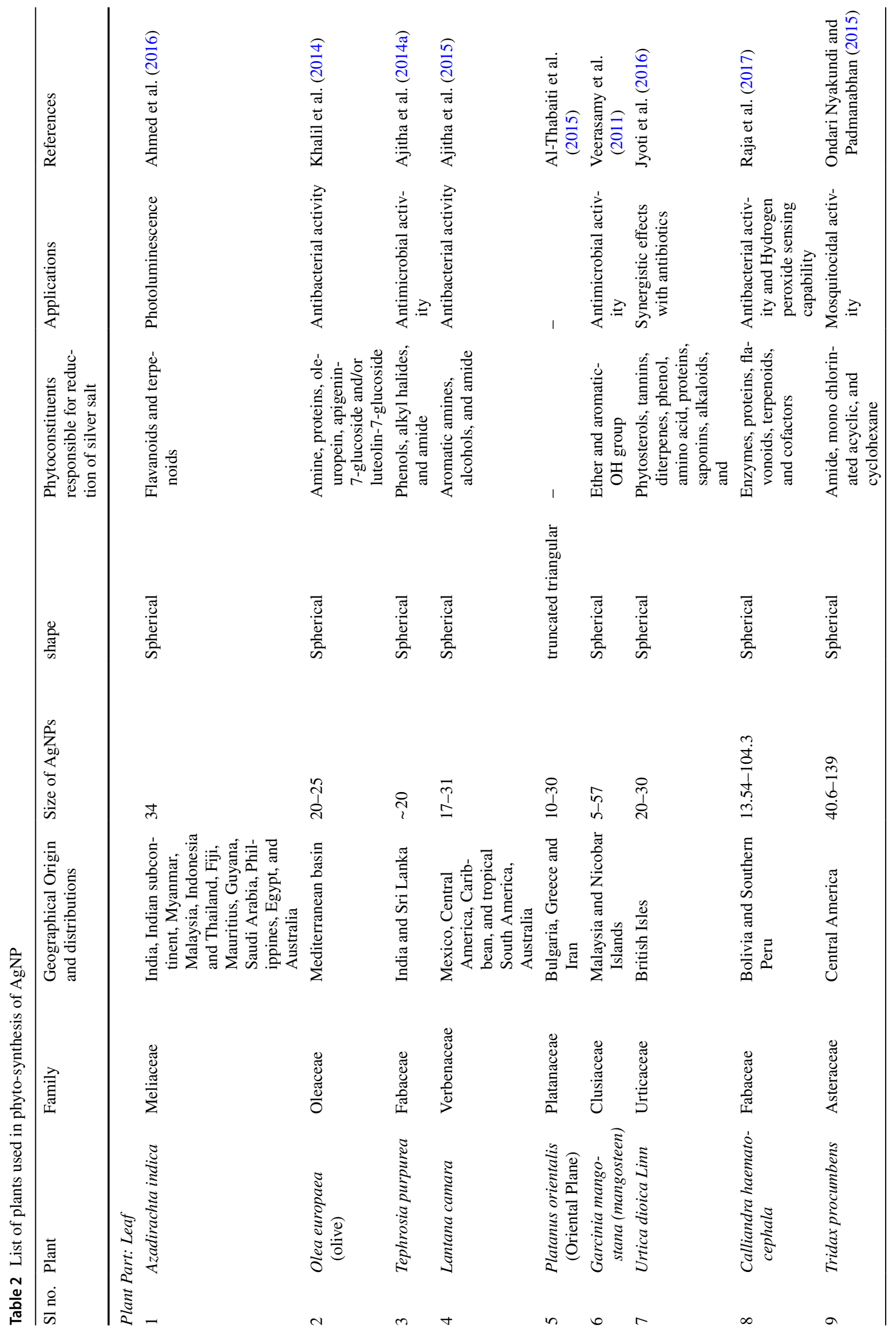




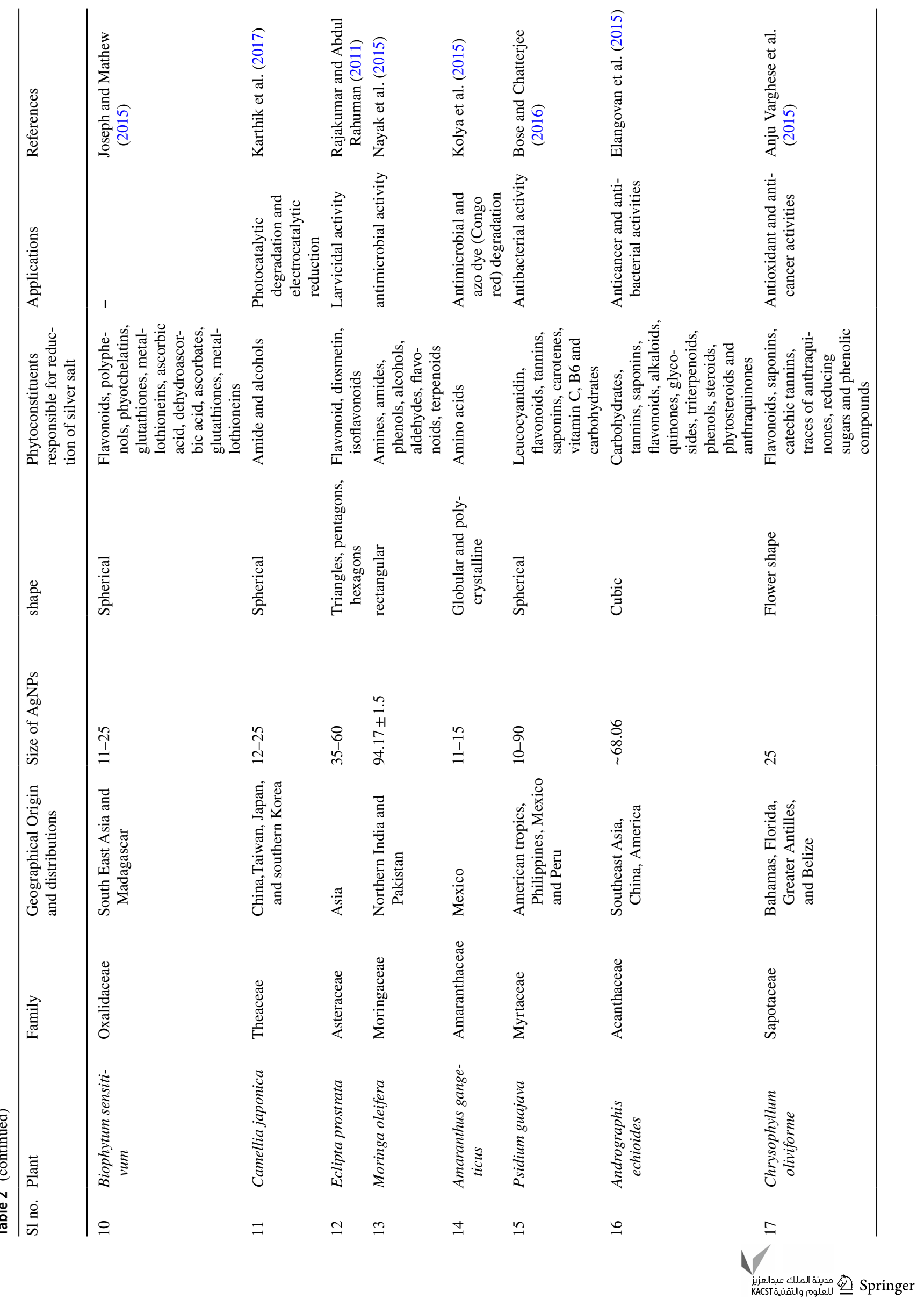




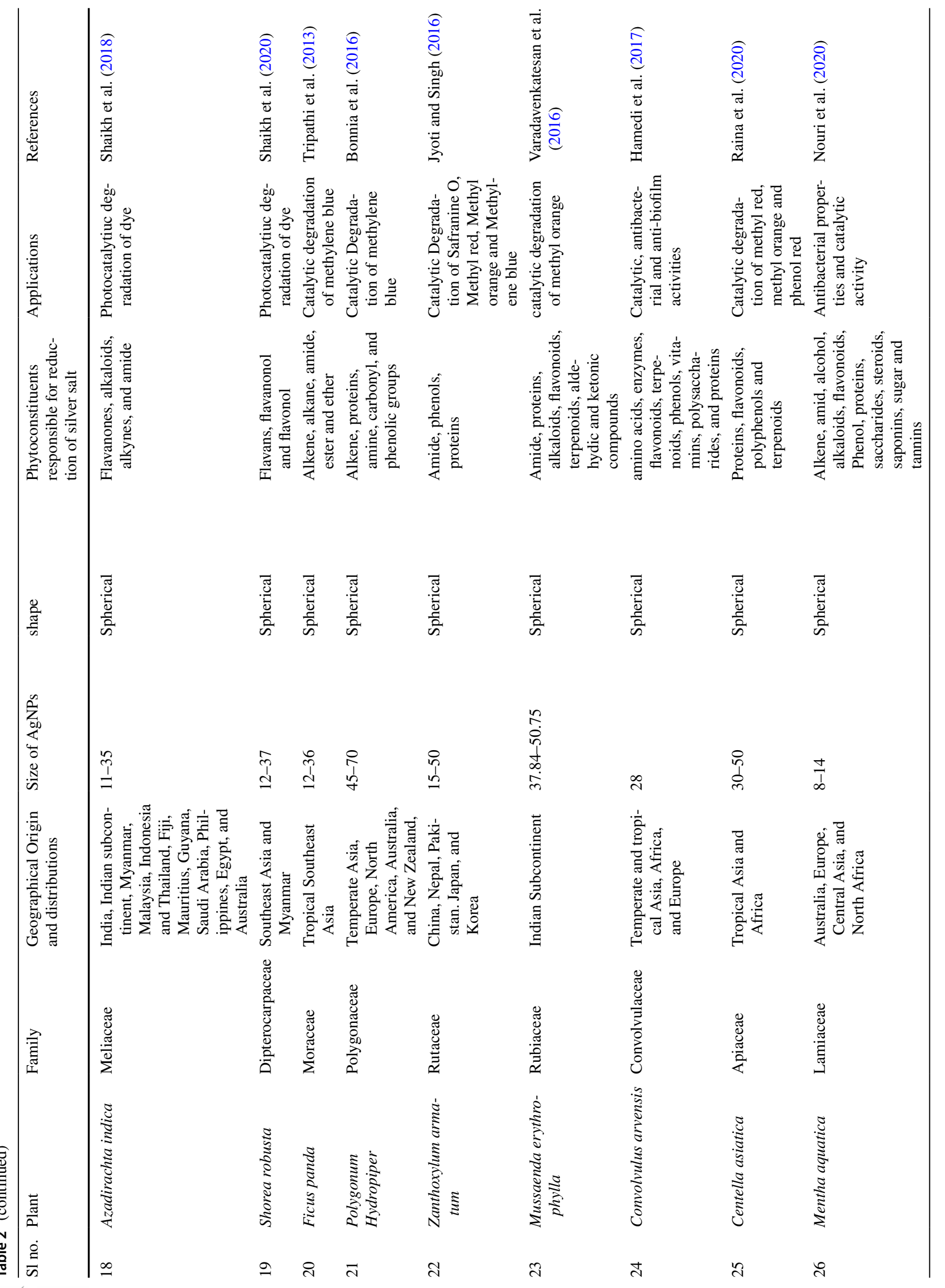




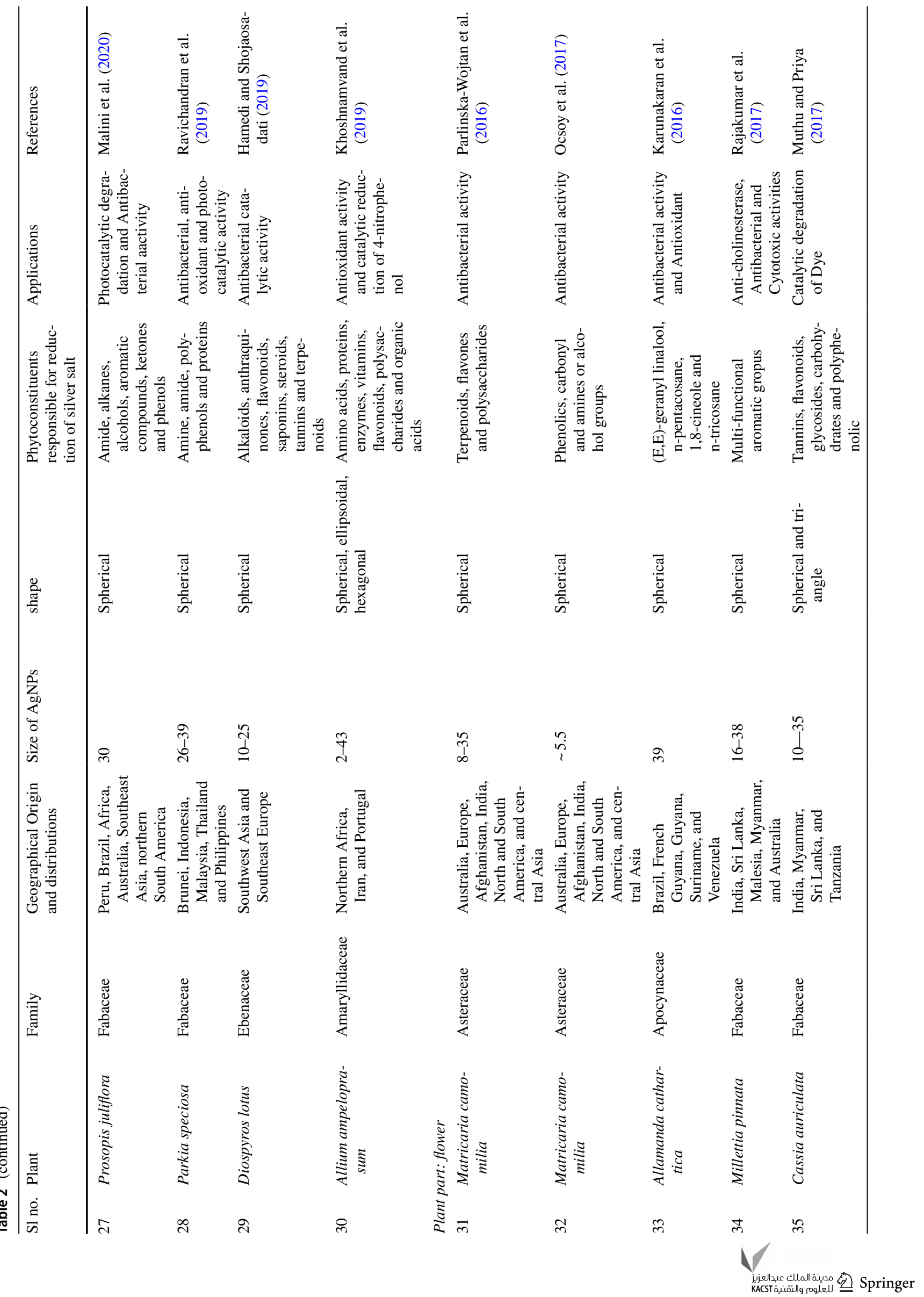




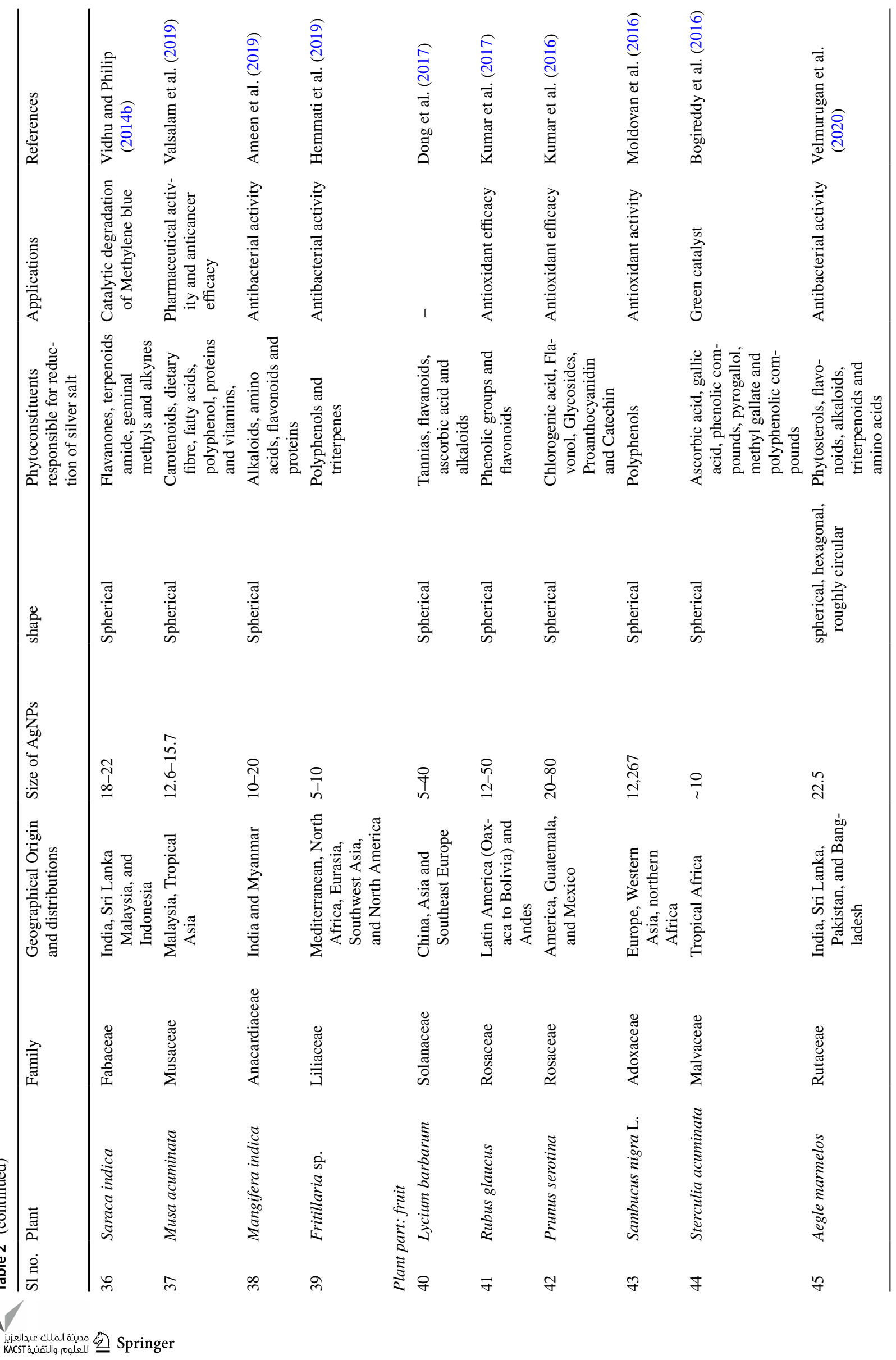




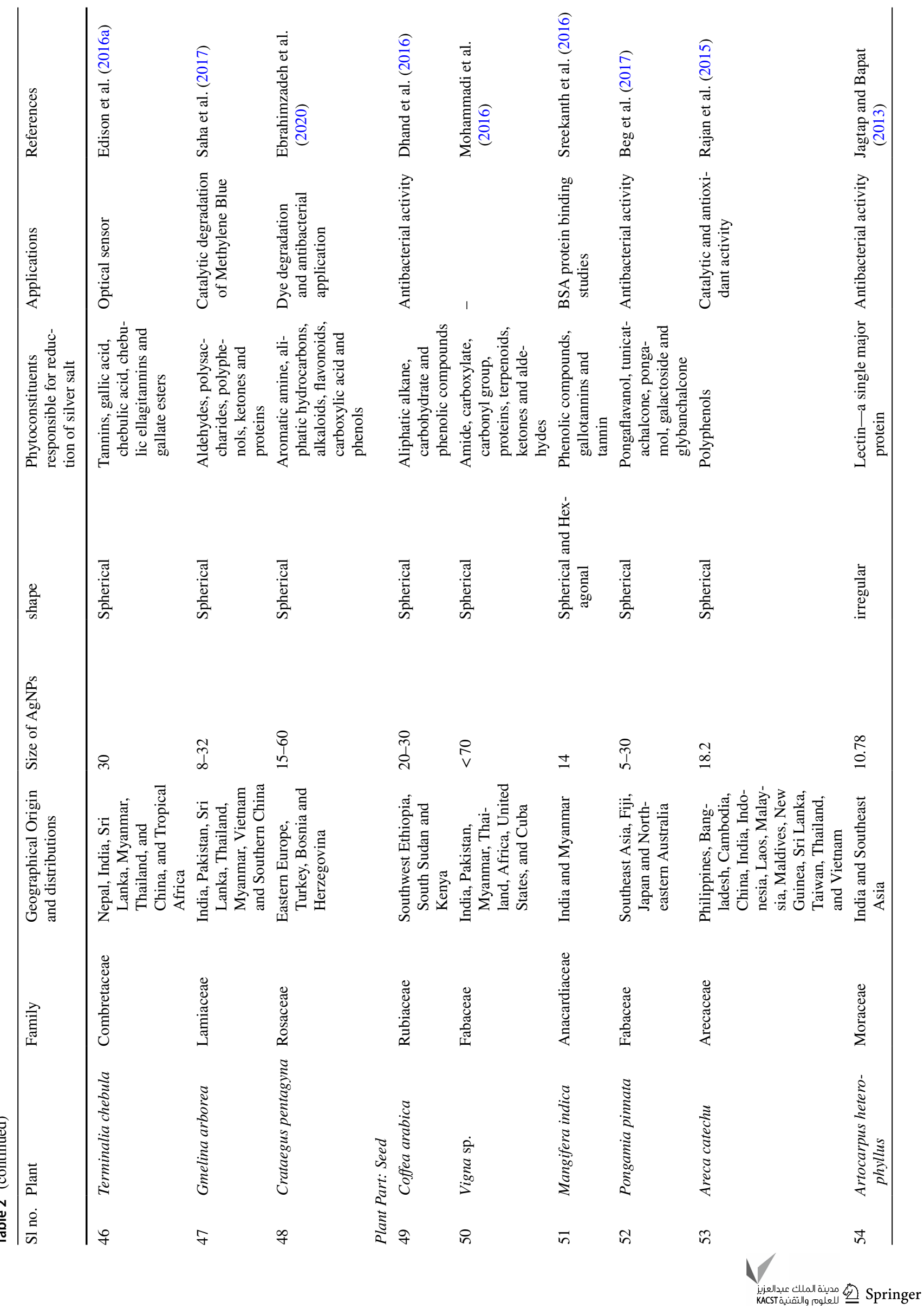




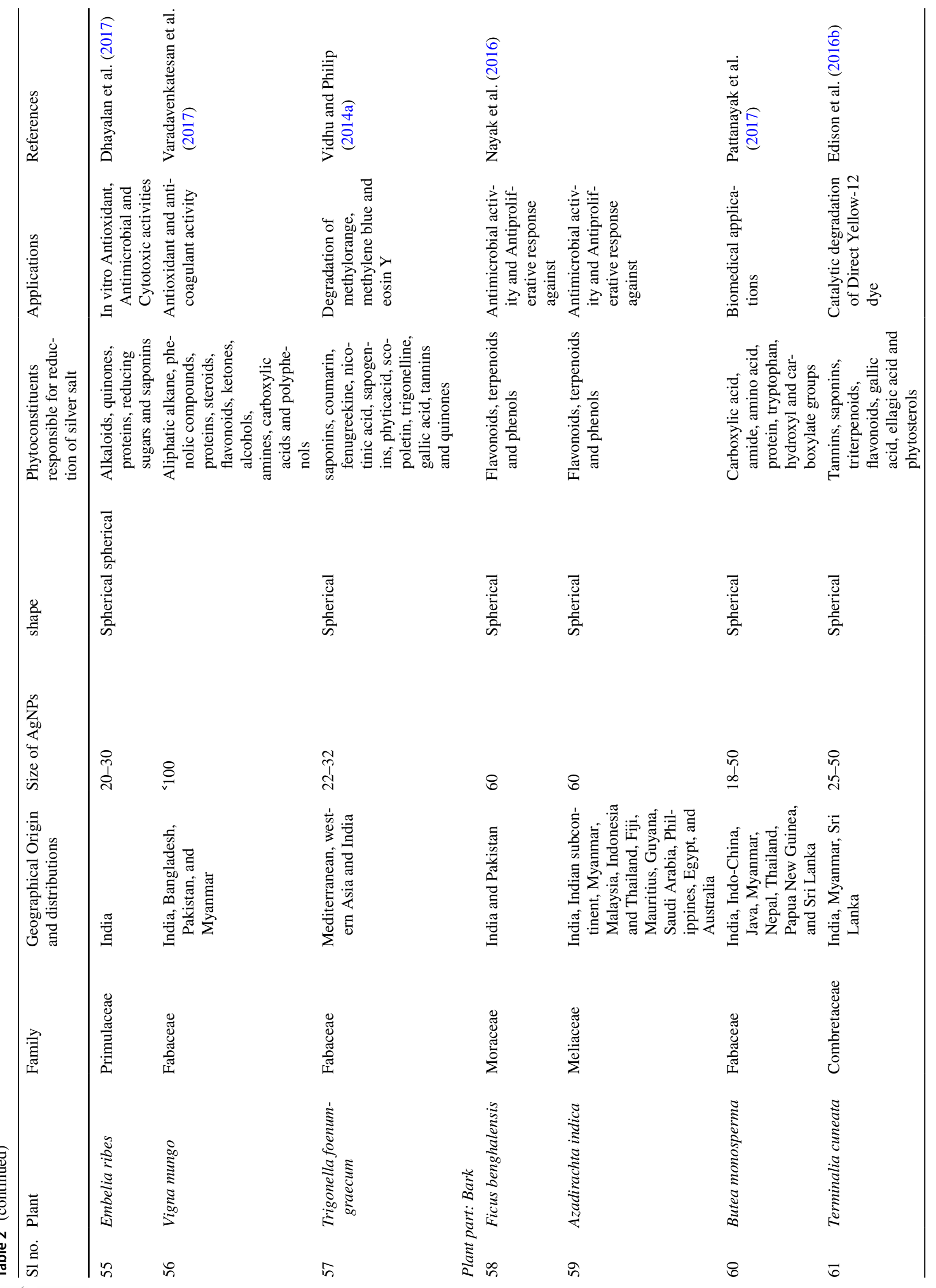




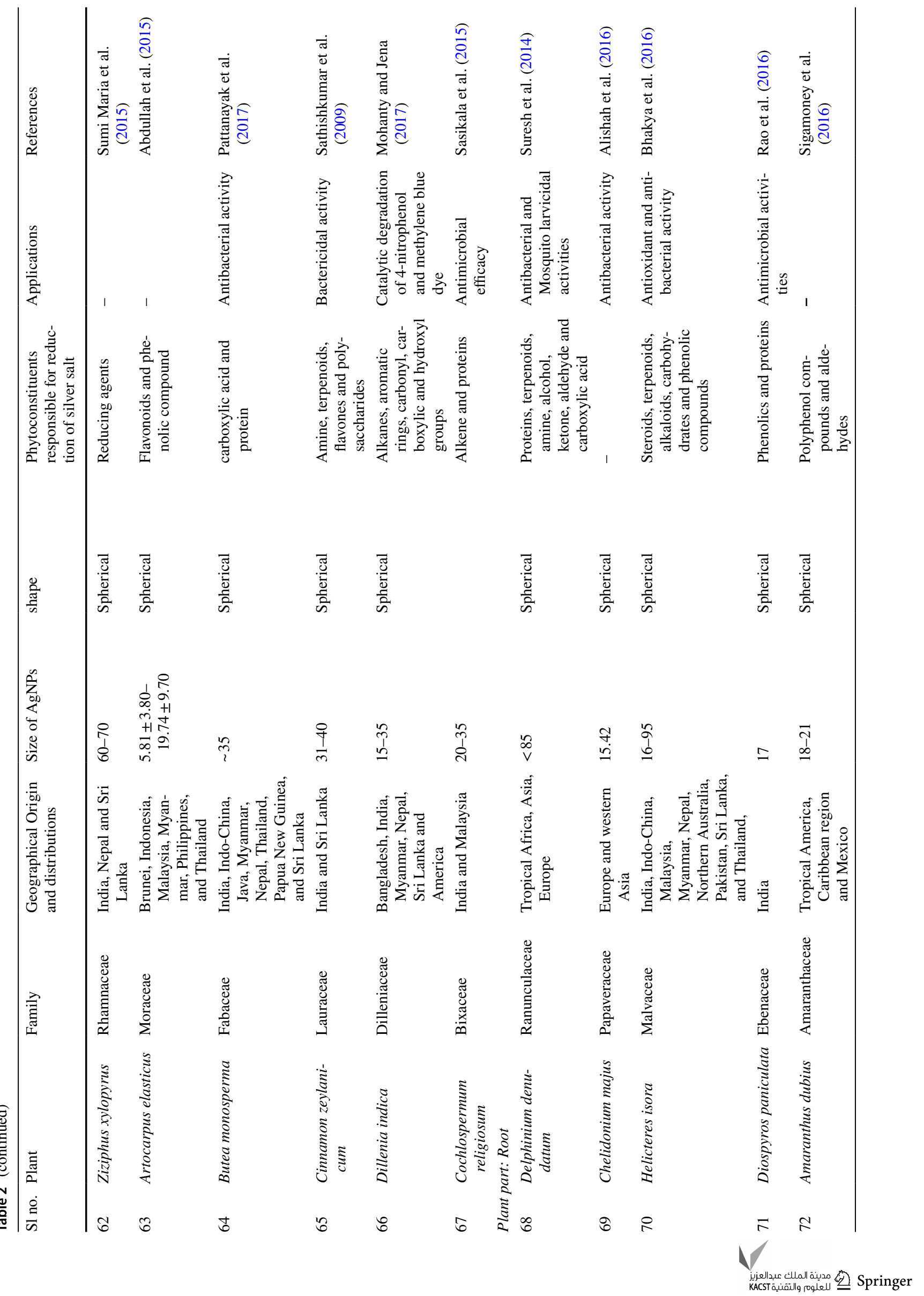




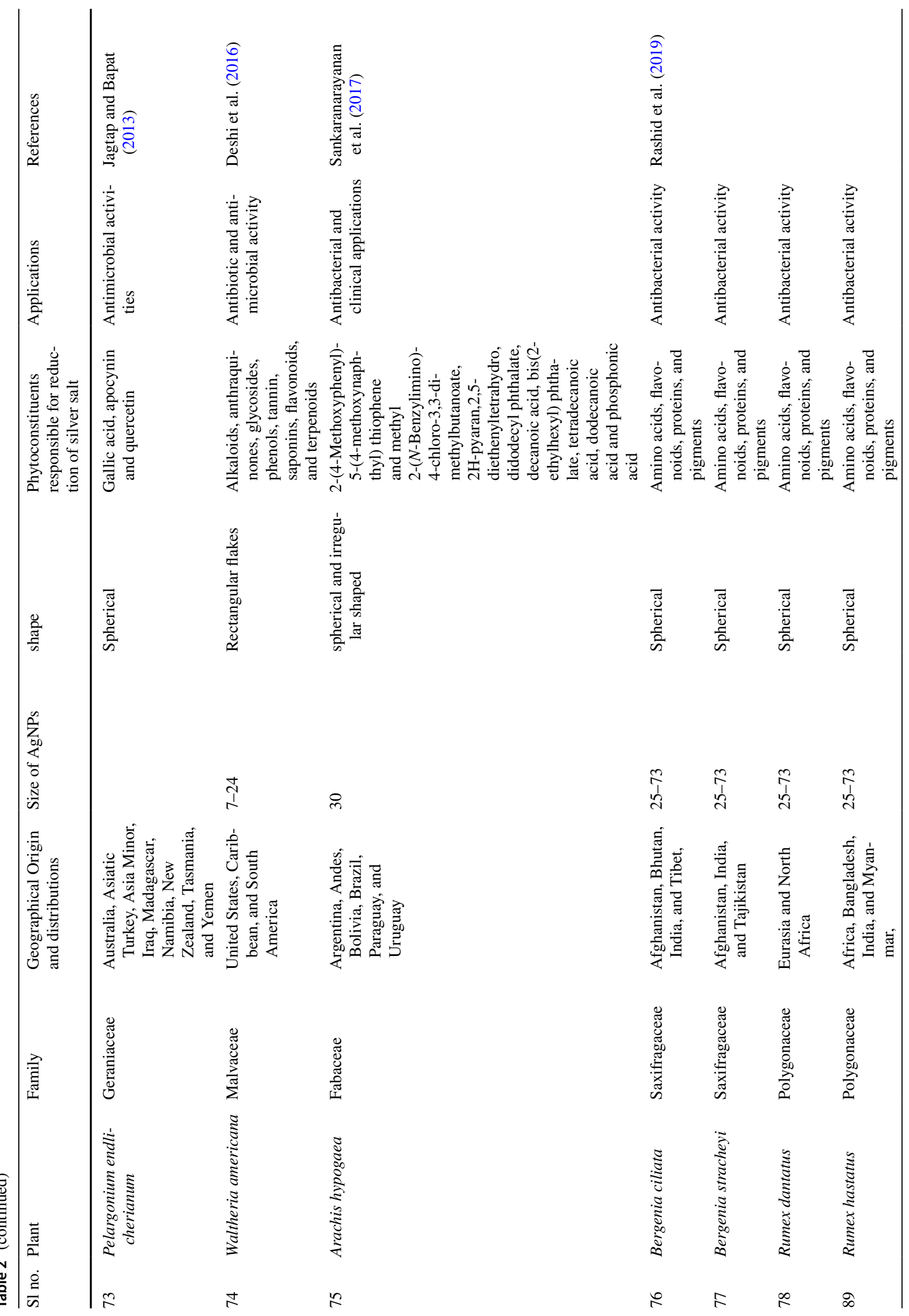




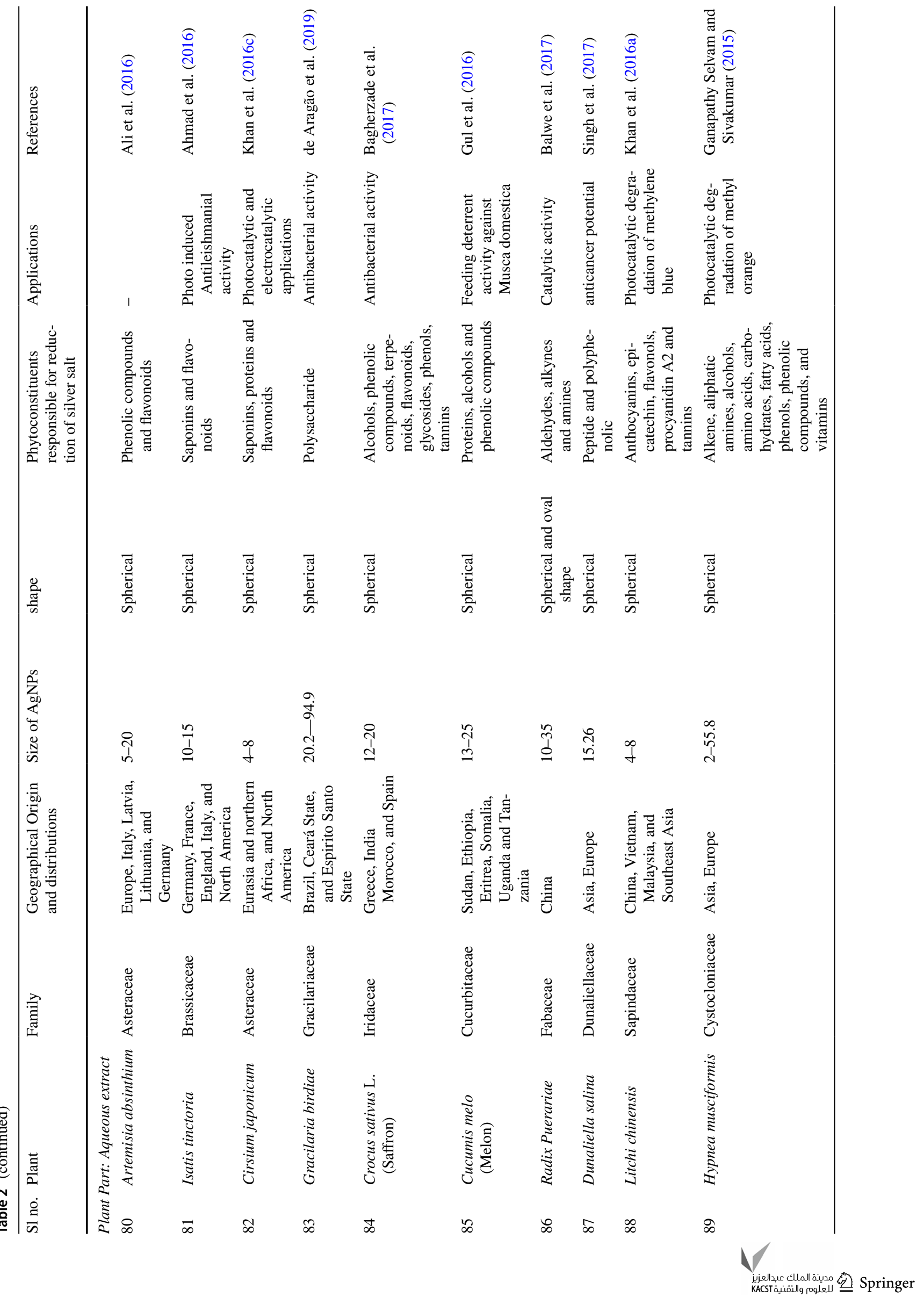




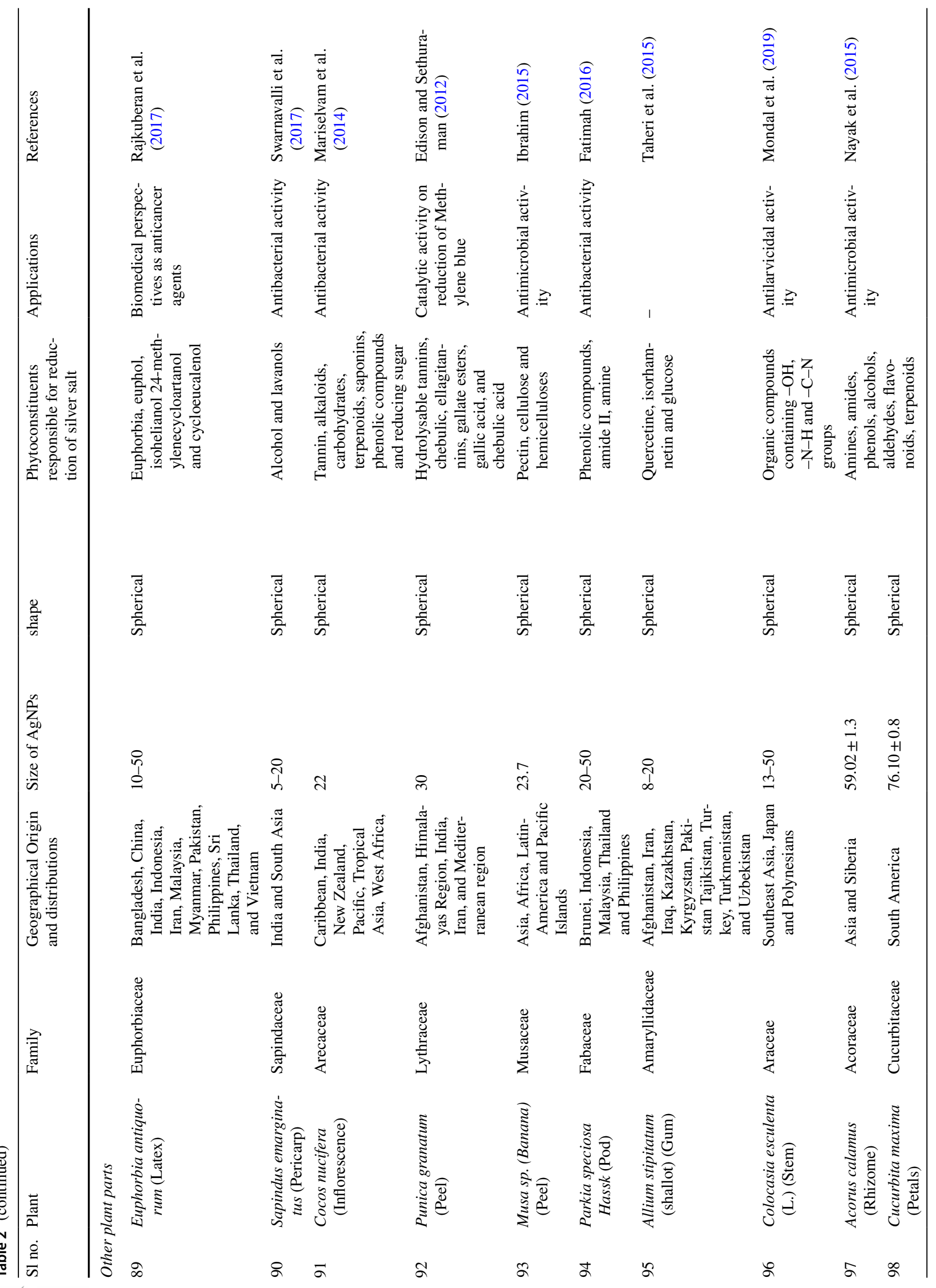




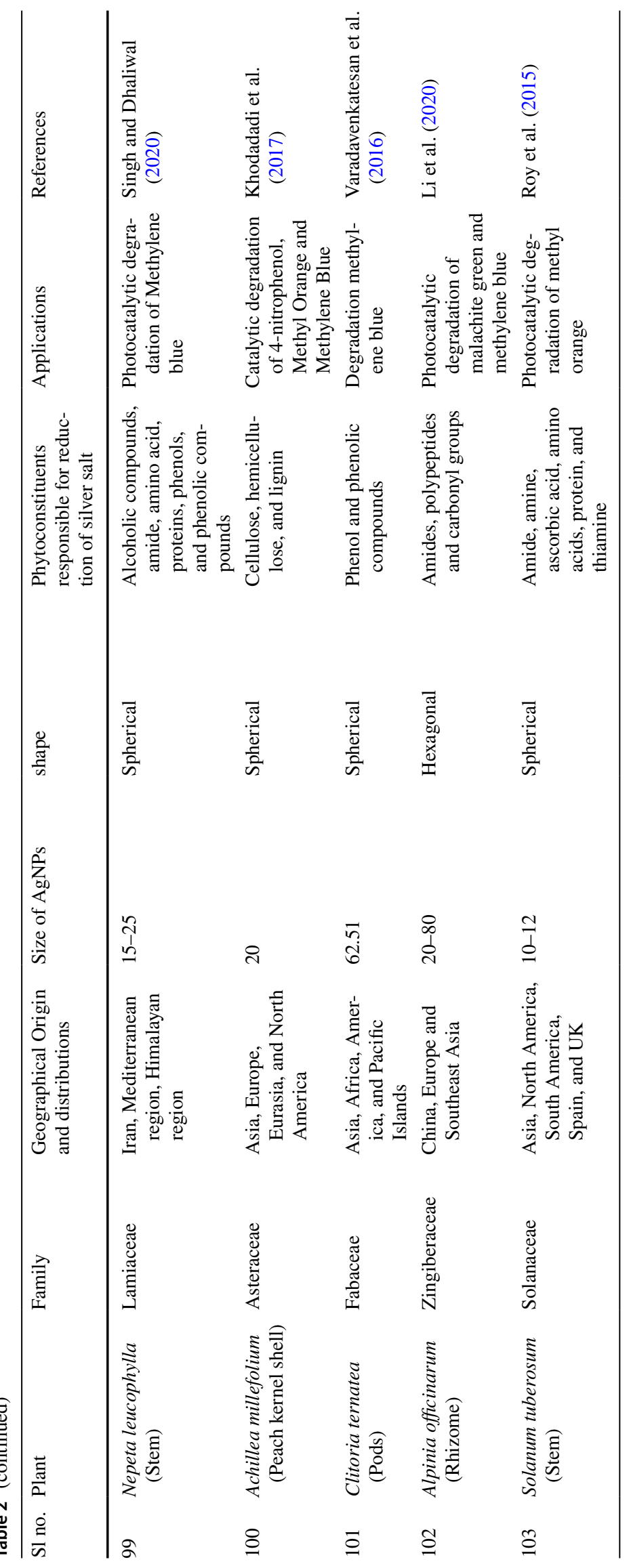


$60 \mathrm{~nm}$. Biomolecules identified as being involved in bioreduction included alcohol, aldehydes, alkanes, amines, amide II, amino acids, carbohydrates, carboxylic acid, carbonyl compounds, cellulose, ester, hemicelluloses, hydroxyl group, lycopene, pectin, phenolic compounds, polyphenol, proteins, vitamins $(\mathrm{C}, \mathrm{K}, \mathrm{E})$, and $\beta$-carotene (Ahmed et al. 2016) (Table 2).

The biosynthesized AgNP showed significant antibacterial activity against Bacillus subtilis, Escherichia coli, Klebsiella pneumonia, Proteus mirabilis, Proteus vulgaris, Pseudomonas aeruginosa Staphylococcus aureus, and Vibrio cholera, (Swarnavalli et al. 2017). It also showed the antibacterial activity towards human pathogens and bloodsucking parasites such as Aedes aegypti and Culex quinquefasciatus (Rajkuberan et al. 2017), anticancer agents (Rajkuberan et al. 2017), antimicrobial activity against bacterial pathogens of humans such as Salmonella paratyphi, Bacillus subtilis, Klebsiella pneumonia, and Pseudomonas aeruginosa (Mariselvam et al. 2014).

\section{Statistics of plant-mediated AgNP synthesis}

Plants are widely distributed throughout the world including both the hydrosphere and lithosphere. Christenhusz and Byng (2016) identified 452 vascular plant families which contain about 308,312 plant species (Angiosperms: 295,383, Gymnosperms: 1079, Lycopods: 1290 and Ferns: 10,560), where the number of the plant species in the largest families (including Asteraceae, Fabaceae, and Orchidaceae) is increasing daily. The global distribution of these newly discovered species is clustered mainly in tropical countries like Australia, Brazil, China, and New Guinea (Christenhusz and Byng 2016). Unfortunately, Joppa et al. (2011) reported that many biodiversity hotspots for these newly discovered plant species were also the most vulnerable. Moreover, the global distribution and economic value of these plant families are quite different. It has been estimated that 17 plant families contribute $\sim 80 \%$ of plantas foods. Orchidaceae as the largest vascular plant family ( $\sim 36$ genera and 28,000 plant species) followed by Asteraceae $(\sim 1623$ genera and 24,700 plant species) and Fabaceae ( 751 genera and 19,500 plant species). Though, Orchidaceae is the largest plant family, in terms of AgNP biosynthesis, the highest number of plant species (31) used was in the Fabaceae family followed by Asteraceae (10) and Lamiaceae (10). Overall our literature review suggests that 221 plant species belonging to 85 families (18.8\% of total plant families found worldwide) were used for the plant mediated AgNP synthesis, might be due to their abundance and presence of the flavonoid compounds (Fig. 4). This might be due to the global distribution, abundance, and most importantly the presence of high quantity of phytochemicals, which reduce $\mathrm{Ag}^{+}$to $\mathrm{Ag}^{0}$ and stabilize AgNP in the colloidal medium.

Among the 221 plant species, there are several plant parts which were sucessfully used in plant-mediated biosynthesis of AgNP. More than 45\% of the plant-mediated biosynthesis of AgNP was conducted using leaves alone. However, some other plant parts including aqueous extract (10\%), fruit $(9.09 \%)$, and root $(7.73 \%)$ were also found to significantly contribute in several studies (Fig. 5). Leaves are the most
Fig. 4 Distribution of the number of plant species within each family used for AgNP biosynthesis

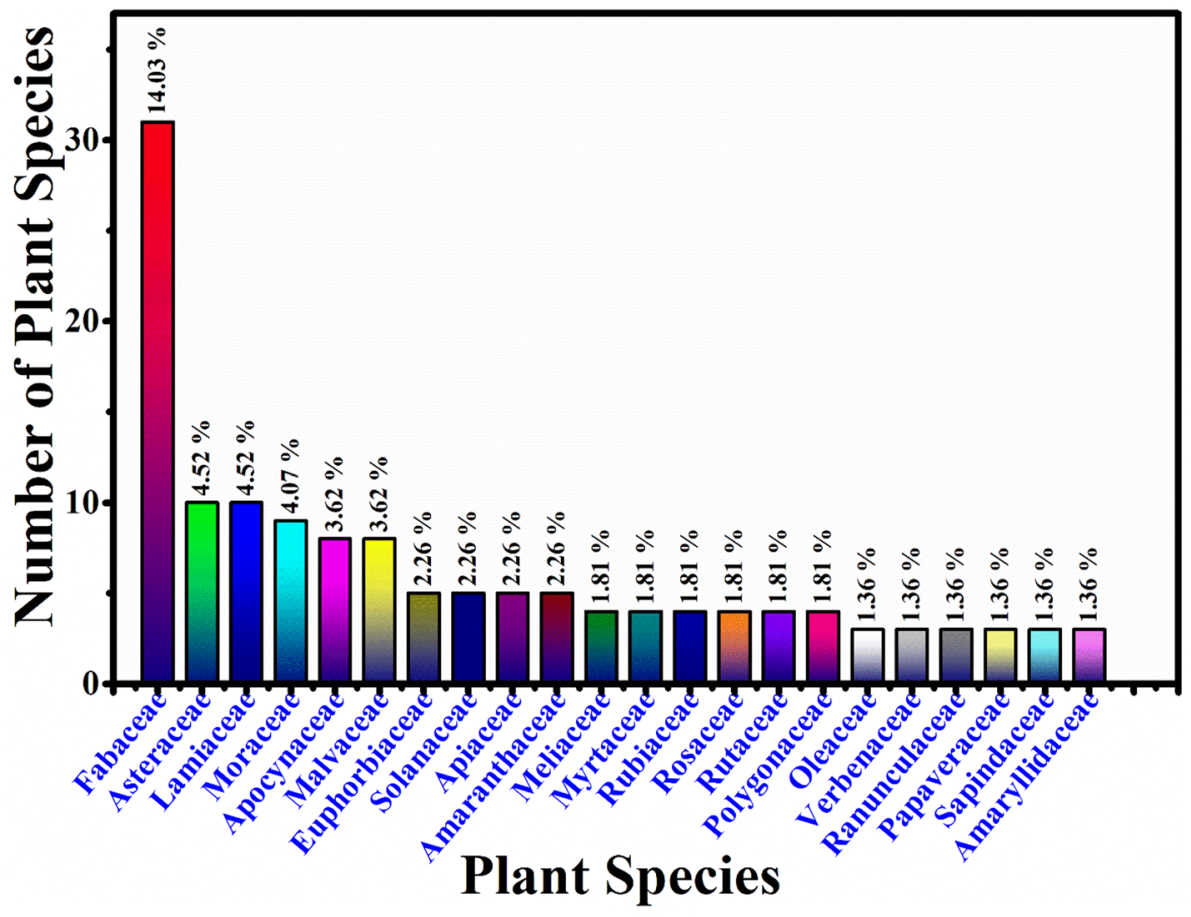


Fig. 5 Distribution of plant parts used for biosynthesis of AgNP

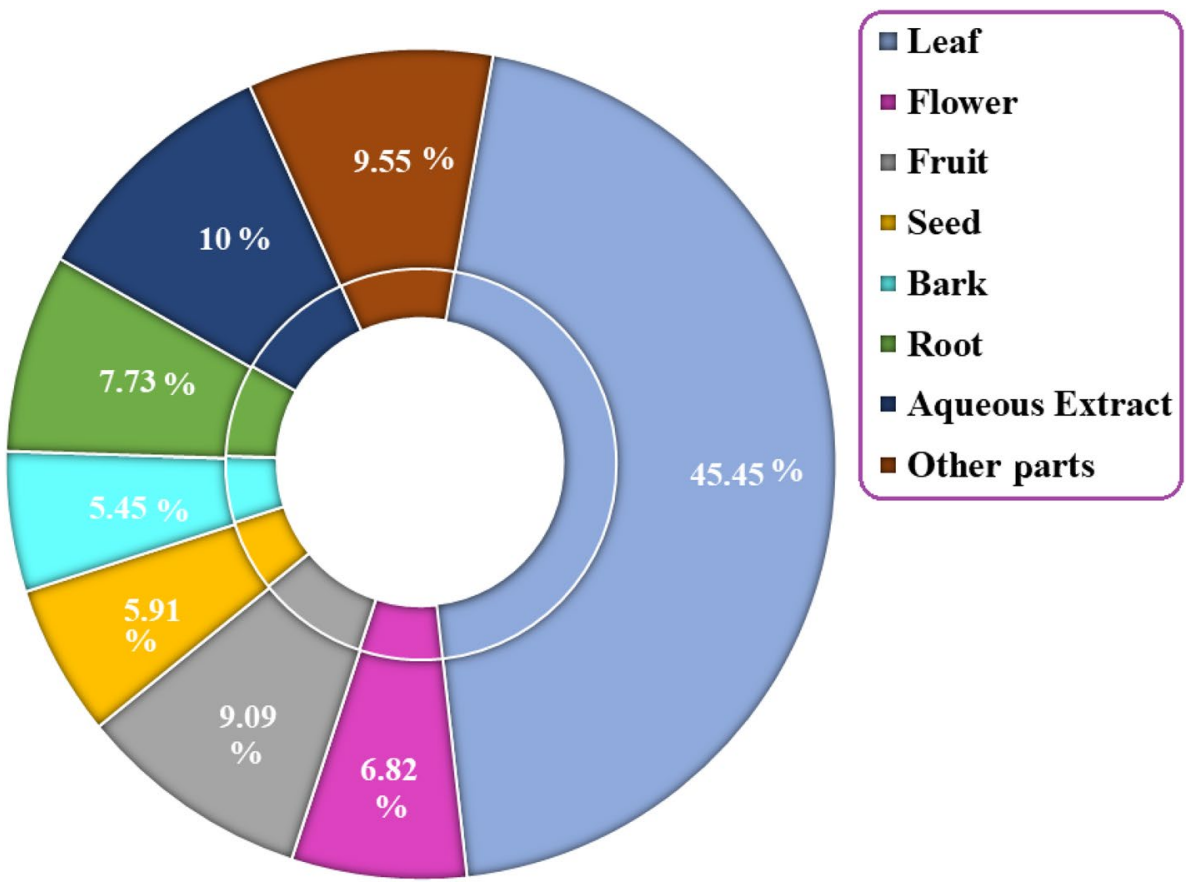

active part of the plant because they geneally contain greater numbers and quantities of phytochemicals including flavonoids, phenolic compounds, and reducing sugars (Altemimi et al. 2017).

\section{Factors affecting plant-mediated biosynthesis of AgNP}

The main challenges in AgNP biosynthesis are the control of crystallinity, shape, size, and dispersity, where the main factors directly influencing these parameters are discussed below.

\section{Effect of precursor concentration $\left(\mathrm{AgNO}_{3}\right)$}

In majority of the plant-mediated biosynthesis of AgNP, $\mathrm{AgNO}_{3}$ has been used as a precursor, and its concentration exhibited a significant impact on the particle size of the resultant NPs. For example, Shaikh et al. (2020) found maximum yield of AgNP with minimum size was achieved at $1.25 \mathrm{mM} \mathrm{AgNO}_{3}$. Zhang et al. (2013) reported optimum biosynthesis of $\mathrm{AgNP}$ at a $\mathrm{AgNO}_{3}$ concentration of $1.0 \mathrm{mM}$, showing that at lower $\mathrm{AgNO}_{3}$ concentrations a wider Surface Plasmon Resonance (SPR) band was formed and upon increasing the $\mathrm{AgNO}_{3}$ concentrations, the product peak become narrower indicating decreasing particle size till the optimum $\mathrm{AgNO}_{3}$ concentration. A similar result was reported by Muthu and Priya (2017) using Cassia auriculata flower extract for spherical and triangular AgNP ranging from 10 to $35 \mathrm{~nm}$ with a $1.0 \mathrm{mM} \mathrm{AgNO}_{3}$ precuser solution also being optimal. Moreover, the investigations of Zhang et al. (2013) also suggested that by increasing the $\mathrm{AgNO}_{3}$ concentration better AgNP (position and shape) were formed and the SPR peak of AgNP trended toward red-shift, indicating larger particle size.

\section{Effect of precursor and phytoextractant ratio (V/V)}

Several earlier works have suggested that the ratio of the precursor to phytoextractant solution on a volume basis could also affect AgNP biosynthesis. This seems reasonable because the biomolecules within the phytoextractants are the key components responsible for both reduction of the Ag salt as well as stabilization of the produced AgNP. It is well established that increasing the phytoextractant dose can not only enhance AgNP yield but also increase the size increase and alter shape up to an optimum ratio (Vijayaraghavan and Ashokkumar 2017).

\section{Effect of reaction time}

The size, shape, and properties of biosynthesized AgNP are significantly influenced by the reaction (or incubation) time for specific plant extractant. Though interspecific variation is evident, incubation time for a specific plant part normally shows an optimum value for effective bio-reduction. Vijayaraghavan and Ashokkumar (2017) reported that the yield and size of AgNP were both positively correlated with incubation time up to an optimum duration. While

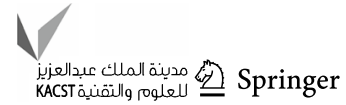


Shaikh et al. (2020) reported complete bio-reduction within 20 min using Flavans, Flavanonol, and Flavonol present in the Shorea robusta leaf extract, Muthu and Priya (2017) reported $99 \%$ bio-reduction of silver ions within $23 \mathrm{~h}$ using a Cassia auriculata flower extract where the main phytochemicals were carbohydrates, glycosides, and polyphenolic compounds. In both the cases, deviation from the optimum incubation period led to decreased yield and size variation. Li et al. (2020) reported the size of AgNP increased with increasing incubation time (with $1 \mathrm{mM}$ $\mathrm{AgNO}_{3}$ ) from $10 \pm 2 \mathrm{~nm}$ at $5 \mathrm{~h}$, to $25 \pm 3 \mathrm{~nm}$ at $9 \mathrm{~h}$ and $40 \pm 5 \mathrm{~nm}$ at $13 \mathrm{~h}$, where the increasing size might be due to the agglomeration of colloidal AgNP.

\section{Effect of pH}

The $\mathrm{pH}$ of the solution medium is an important parameter that influences both the rate, shape, and size of plant-mediated biosynthesised AgNP. For example, Sathishkumar et al. (2009) found that when using a Cinnamom zeylanicum bark extract for bio-reduction over a wide $\mathrm{pH}$ range (1-11) large ellipsoidal AgNP formed at acidic $\mathrm{pH}\left(\mathrm{pH}^{<} 7\right)$, whereas smaller spherical AgNP formed at alkaline $\mathrm{pH}(\mathrm{pH}>7)$. This was attributed to the presence of a larger numbers of functional groups at higher $\mathrm{pH}$, leading to nucleation at higher $\mathrm{pH}$ while at lower $\mathrm{pH}$ aggregation was favoured over nucleation. Nucleation increases with increasing solution $\mathrm{pH}$ indicating the formation of $\mathrm{Ag}^{0}$ from $\mathrm{Ag}^{+}$due to bio-reduction. At the same time, the solution $\mathrm{pH}$ also influences the rate of bio-reduction by influencing the activity of the phytochemicals (Veerasamy et al. 2011). For example, it was suggested that better AgNP formation occurred under basic conditions with 0.1-2.0 $\mathrm{mM} \mathrm{AgNO}_{3}$ and efficiency decreased with decreasing $\mathrm{pH}$ of the reaction medium (Yazdi et al. 2019). Furthermore, AgNP synthesized in acidic medium (pH 4) yielded larger particle size, whereas highly dispersed and small-sized AgNPs were observed at pH 8 (Khandan Nasab et al. 2020). This phenomenon revealed enhancement of nucleation *centres with increases in solution $\mathrm{pH}$. The result also suggested that at lower $\mathrm{pH}(<7)$ large number of functional groups of phytochemicals bind with AgNP increasing the chance of agglomeration, resulting in larger sized AgNP (Veerasamy et al. 2011). However, Ondari Nyakundi and Padmanabhan (2015) suggested that as a soft metal, Ag binds with soft ligands like amino and sulfhydryl groups, where these positive charged groups then reduce $\mathrm{Ag}^{+}$to $\mathrm{Ag}^{0}$ at low $\mathrm{pH}$. The bio-reduction was thus mainly through ionic binding and phytochemicals which was favoured at low $\mathrm{pH}$ due to the presence of positively charged functional groups. The study also suggested the involvement of some hard ligand-like carboxylic groups which became protonated at low $\mathrm{pH}$ and also helped to in the formation of AgNP. It is also evidential from examination of the literature that the zeta potential of acidic colloidal AgNP is generally lower than that of alkaline colloidal AgNP. Rapid bio-reduction with highly dispersed AgNP and negative zeta potential was observed at higher $\mathrm{pH}$ (Akhtar et al. 2013).

\section{Effect of temperature}

Temperature is yet another key factor that significantly affects the shape and size of biosynthesized AgNP with a positive correlation between temperature and AgNP yield up to an optimum temperature, normally around $27^{\circ} \mathrm{C}$ for 0.5-3.0 mM AgNO 3 (Akhtar et al. 2013; Kumar et al. 2021a). Verma and Mehata (2016), when investigated AgNP biosynthesis using a Azadirachta indica leaf extract at different temperatures ranging from 10 to $50{ }^{\circ} \mathrm{C}$, found that AgNP size decreased with increasing temperature upto $27{ }^{\circ} \mathrm{C}$, which might be due to an increased bio-reduction rate with increasing temperature. Most studies agree that smaller and more uniformly distributed AgNP are produced at room temperatures (around $27^{\circ} \mathrm{C}$ ). Increasing temperature (beyond room temperatute; $27^{\circ} \mathrm{C}$ ) resulted in larger sized AgNP, potentillay due to the denaturation of phytochemicals and increasing agglomeration of AgNP (Ahmed et al. 2016). However, as with many studies, this article failed to idenify the specific phytochemicals responsible for changes in the size of AgNP with increasing temperature.

\section{Mechanism of the biosynthesis process}

The biochemical composition of plant extacts may vary considerably with the plant species or even within the same plant when different plant parts are extracted. While a wide range of phytochemicals, commonly implicated in either bioreduction and/or stabilization are known and listed breifly in the Sect. 4.1, the extact mechanistic role this chemical play is not always clear. None of these articles clearly indicated or identified the specific active biomolecules responsible for the bio-reduction process of $\mathrm{Ag}^{+}$to $\mathrm{Ag}^{0}$. Jha and Prasad (2010) reported that some metabolites can trigger the bioreduction process via transformation of silver ions to AgNP due to redox activity of dehydroascorbic acid/ascorbic acid or amenti/hinoki flavones or some other metabolite. Some researchers reported that the carbonyl and hydroxyl groups of flavonoids, terpenoids, carbohydrates, and phenolic compounds as reducing agents, played a key role in the reduction of $\mathrm{Ag}^{+}$ions to metallic $\mathrm{Ag}^{0}$ nanoparticles (Ajitha et al. 2015). Proteins, peptides and the carbonyl groups of amino acid have all been shown to have strong affinity to bind with metallic $\mathrm{Ag}^{0}$ to form a coating layer around the AgNP that assists colloidal stabilization in solution (Fig. 6) (Karthik et al. 2017). These authors also claimed that the quantity 


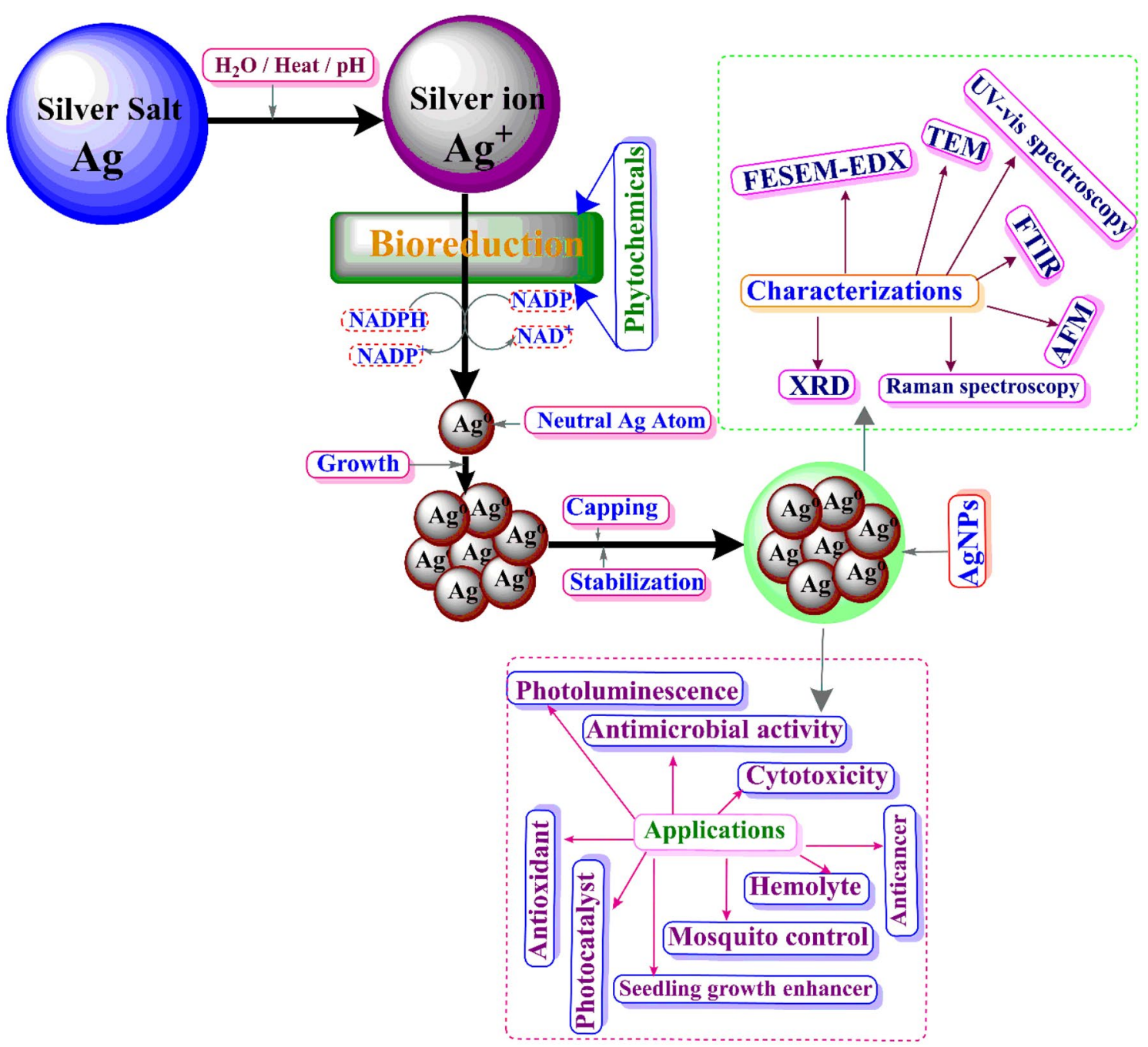

Fig. 6 Probable bio-reduction mechanism of silver salts $\left(\mathrm{AgNO}_{3}\right)$ leading to the formation of $\mathrm{AgNP}$

of leaf extract used in the experiment has an important role in regulating the size of the nanoparticles and inhibited the oxidation of the produced AgNP (Ajitha et al. 2015).

Extracts of Desmodium trifolium were successfully used to biosynthesise AgNP via reduction of silver ions where the presence of ascorbic acid in the extract played a significant role (Ahmad et al. 2011). Previously, Kesharwani et al. (2009) had also reported a bio-reduction mechanism when using Datura metel to produce stable AgNP havin a particle size between 16 and $40 \mathrm{~nm}$. However, rather than ascorbic acid, this study had shown that the D. metel leaf extract contained a wide varieity of enzymes, amino acids, alkaloids, proteins, and polysaccharides these were responsible for bio-reduction.

However, in all of these studies, while a mechanism was propsed involving simultaneous reducing and/or capping biomolecules, none of the studies could unambiguously identify the specific phytochemicas involved in each role.

\section{Role of phytochemicals in the biosynthesis of AgNP}

The bio-inspired routes for AgNP synthesis are attractive because they not only produce nontoxic and inexpensive nanoparticle in a one-step synthesis but, also depending on the interaction between AgNP and the phytochemical capping agents present, the AgNPs so produced are often produced with controllable size and morphology.Therefore, it is important to identify and understand the specific interaction(s) between the phytochemicals present in the extracts and the silver salts in solution which react to produce AgNP. While a vast myriad of phytochemicals including amides, flavonoids and peptides for example (details listed in Sect. 2) have been identified as being involved in AgNP biosytheis, the specific interaction of all phytochemicals is yet to be conclusively established. 
Trouillas et al. (2006) employed a density-functional theory (DFT) method to investigate the interactions during bioreduction of a silver salt which showed that the $\mathrm{O}-\mathrm{H}$ bond dissociation energies of the hydroxyl group of the catechol moiety of flavonoids was less than that of other $-\mathrm{OH}$ groups present in most phytochemicals. Similar result was reported by Bose and Chatterjee (2016) for the biosynthesis of AgNP using a Psidium guajava leaf extract. These results indicated that the carbonyl and hydroxyl groups of flavonoids play a significant role in the reduction of $\mathrm{Ag}$ ions through the metal chelation with the catechol moiety of flavonoids, where the electrostatic interaction and charge transfer between the $\mathrm{OH}$ group of flavonoids and $\mathrm{Ag}^{+}$ion are responsible for biochemical interaction leading to bio-reduction. Shaikh et al. (2020) also reported three specific flavonoids (Flavan-3-ol, Flavan-3,4-diol, Flavan-4-ol) acted as reducing and/or capping agent for the reduction $\mathrm{Ag}^{+}$to $\mathrm{Ag}^{0}$ (Fig. 7), during the biosynthesis of AgNP using a Shorea robusta leaf extract. This bio-reduction mechanism might be due to the tautomeric transformations of flavonoids to flavone and/or flavonol (from enol to keto), where the reactive hydrogen was

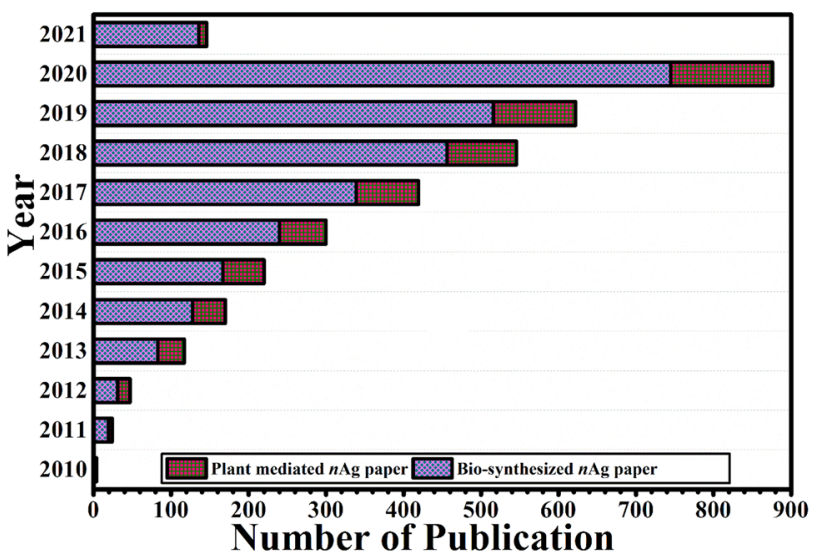

Fig. 8 Year wise number of publications of bio-synthesized AgNP and plant mediated bio-synthesized AgNP

released by some hydroxyl $(-\mathrm{OH})$ containing groups including Flavans, flavanonol and flavonol (Shaikh et al. 2020).

The review was conducted to identify the trends emerging in nanoparticle research using an open-access database
Fig. 7 Role of phytochemicals in the biosynthesis of AgNP

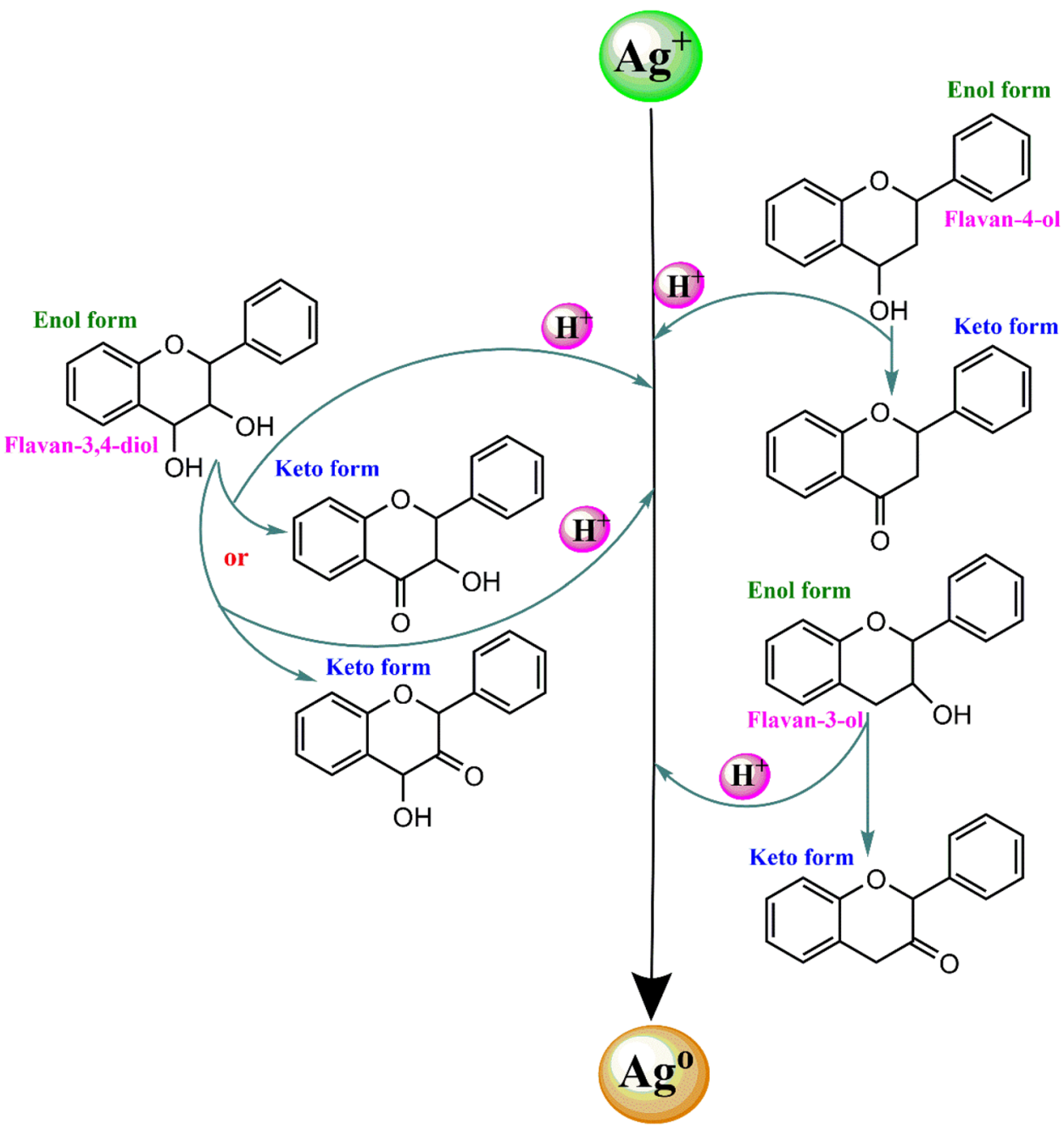


search engine (Dimensions), and VOSviewer software (version 1.6.16) for data analysis to acquire a holistic view of the current trends in AgNP synthesis. Research articles published during 2008-2021 (till 31st January 2021) were considered in this statistical analysis (Fig. 8a). Among the 115 million publications searched, 2877 research articles were found for the search term 'bio-synthesized silver nanoparticles', where only 629 research articles were also related to 'plant-mediated bio-synthesized silver nanoparticles'. For this search, we used two keywords, "biosynthesized silver nanoparticles" and "plant-mediated silver nanoparticle synthesis" under the "research article" section only.

The refined search criteria yielded 2877 research articles published in the 65 most common journals in the fields of science, technology, and engineering, where $\sim 50 \%$ of articles were published in the 14 major analytical and environmental chemistry journals (Fig. S1). Most studies (>65\%) were published between 2013 and 2020, indicating a growing interest in the advancement of analytical techniques in the field of nanotechnology. It was observed from the analysis that though initially, these studies were only focused on the AgNP biosynthesis, from 2015 onwards, focus shifted to environmental pollution control domain from only biosynthesis of AgNP (Fig. 8). Moreover, an analysis on the research articles based on 'plant-mediated silver nanoparticle synthesis' in the past decade (2010-2020) showed that the number of publications in the 1st and 2nd quarter (2010-2016) was gradual. However, a significant increment was observed at the end of the 2 nd quarter (after 2013-2014).

The first research article on plant-mediated bio-synthesized silver nanoparticles was published by Rajasekharreddy et al. (2010), which reported biosynthesis of both AgNP and gold nanoparticle $(n \mathrm{Au})$ using the leaf extracts of Calotropis gigantea L. (Calotropis), Carica papaya L. (Papaya), Citrus aurantium L. (Bitter orange), Datura metel L. (Datura), Jatropa curcas L. (Barbados nut), Solanum melongena L. (Eggplant), and Tridax procumbens L. (Coat buttons) using the sunlight exposure method. Moreover, the network map of 2792 authors with a citation weightage, represented in Fig. 9a, showed that the research group of Prof. Giovanni Benelli of University of Pisa, Italy, Prof. Kadarkarai Murugan of Bharathiar University, India, Dr. Chellasamy Panneerselvam of University of Tabuk, Saudi Arabia and Prof. Zia Ul Haq Khan of University of Engineering and Technology Peshawar, Pakistan were the major contributor in the field of 'plant-mediated bio-synthesized silver nanoparticles'. It was also seen from Fig. 9b that Prof. Giovanni Benelli had the highest number of articles (10) of plant-mediated AgNP synthesis, owing to the highest total link strength (344), followed by Prof. Kadarkarai Murugan (number of articles 9; total link strength 229). The highest citations and the highest total link strength indicated the novelty, reliability of the phenomenon, and acceptability in the scientific community which swiftly triggered the progress and advancement of the field of nanoparticle research, more precisely in the field of plant-mediated AgNP research. Some of the researchers (Prof. Zia Ul Haq Khan; Number of articles 7 of plantmediated AgNP synthesis; Total link strength 90) have a high number of papers but lower total link strength indicating the resecach articles are not cited in this field. However, Dr. Chellasamy Panneerselvam has only 6 articles related to plant-mediated AgNP synthesis owing total link strength of 200 indicating the higher citation rate and acceptability of his articles.

From the 629 published research articles on AgNP across 67 countries, it was found that the research was predominantly conducted in Asia compared to Europe, America, and Africa. The result showed most of the research articles were published by India (258), followed thereafter by China (58), and least among among European countrries, where Italy (12) had the highest number of published on AgNP papers, and Nigeria (11) had the highest AgNP papers in Africa (Fig. S2), while Australia and the USA contributed 5 and 30 papers of AgNP, respectively. The incremental sequence in the greatest number of published AgNP papers $(>10)$ was India $>$ China $>$ Pakistan $>$ Saudi Arabia $>$ Iran $>$ USA $>$ South Korea $>$ Malaysia $>$ Egypt $>$ South Africa $>$ Mexico $>$ Italy $>$ Nigeria. Nineteen per cent of the countries in the database, including India, China, Pakistan, Iran, Malaysia, Mexico, Egypt, and Nigeria, had ten or more research articles contributing $>95 \%$ plant-mediated $\mathrm{AgNP}$ articles (Fig. 10).

Similarly, the data were also examined for citation analysis considering a minimum threshold limit of three published research articles from a country, which showed India to be the largest contributor with 258 articles, followed by China with 58 (Fig. 10). Moreover, India has the highest total link strength (1218), indicating Indian studies were cited by most other countries as a reliable source of information in this field. The spread of research mainly clustered in Asia revealed strong bias at the continental scale, having $>60 \%$ of the total citation between 2008 and 2021. In North America, South America, Europe, and Africa, the cluster centred in the USA, Mexico, Italy, and South Africa, respectively.

This bibliometric study showed good knowledge of plant-mediated AgNP synthesis in Asian countries like India, China Pakistan and some Europian countries. Among these, India is one of the pioneers and most experienced country in the field of plant-mediated AgNP research. The enhanced research in this country might be due to the following: (1) availability of numerous plants due to geographical location and wide ranges of climatic conditions, (2) significant development in the field of nanoscience and nanotechnology, and (3) directionless research, 


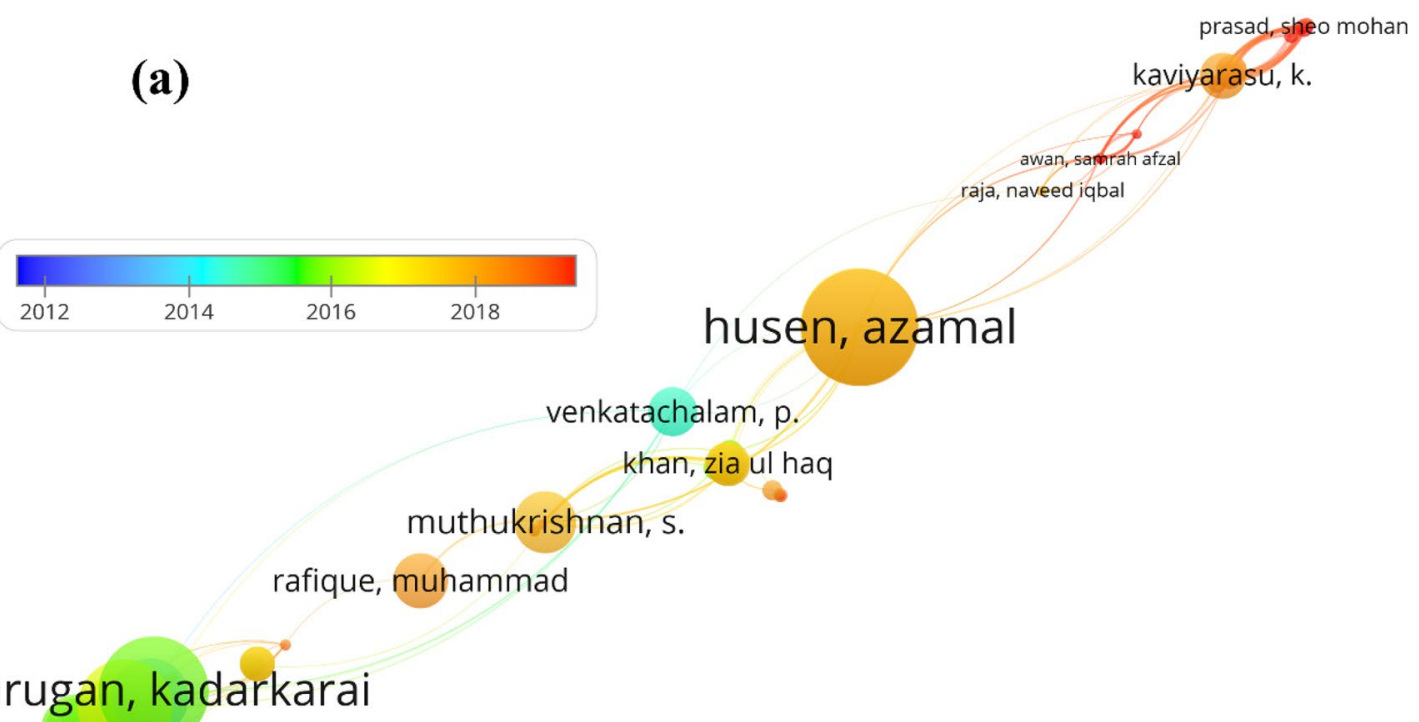

\section{murugan, kadarkarai}

\section{Vosviewer}

(b)

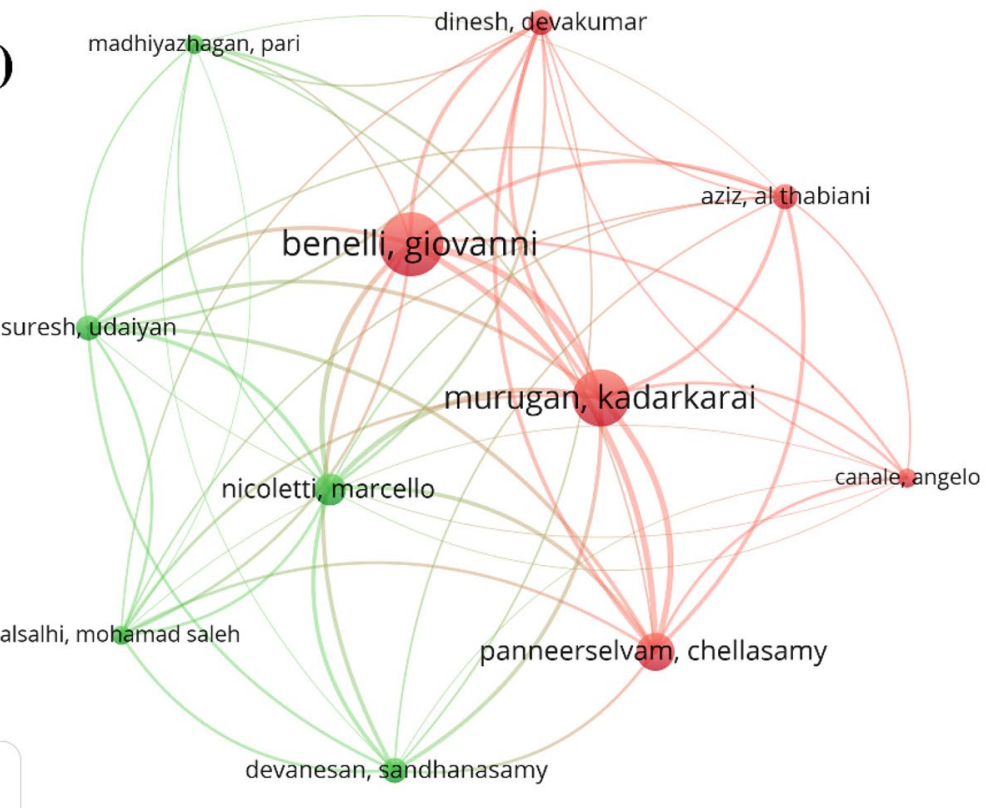

Fig. 9 a Citation of authors for the publication of plant-mediated AgNP papers and $\mathbf{b}$ Bibliometric network of authors for plant-mediated biosynthesized AgNP

which generally followed the previous one (changing the plants and applications) to publish a paper without realizing the significance and feasibility for real application. However, this study also showed that AgNP research was deficient or even absent in a considerable part of the globe, mostly in poor and developing countries of South America and Africa. The major reason behind this could be less nanotechnology development and lower funding in theses regions resulting in the observed publication gap.
Moreover, some research articles were focused on AgNP biosynthesis and detailed sampling techniques and preservations in the 2 nd and 3rd quarters of the decade (Ahmed et al. 2016). Among the different sampling technique, nonrepeated grab sampling was a commonly adopted technique for the collection of most of the plant samples (Mohammadi et al. 2016). However, some repeated grab sampling and composite sampling were also observed in some of the studies (Raja et al. 2017). 


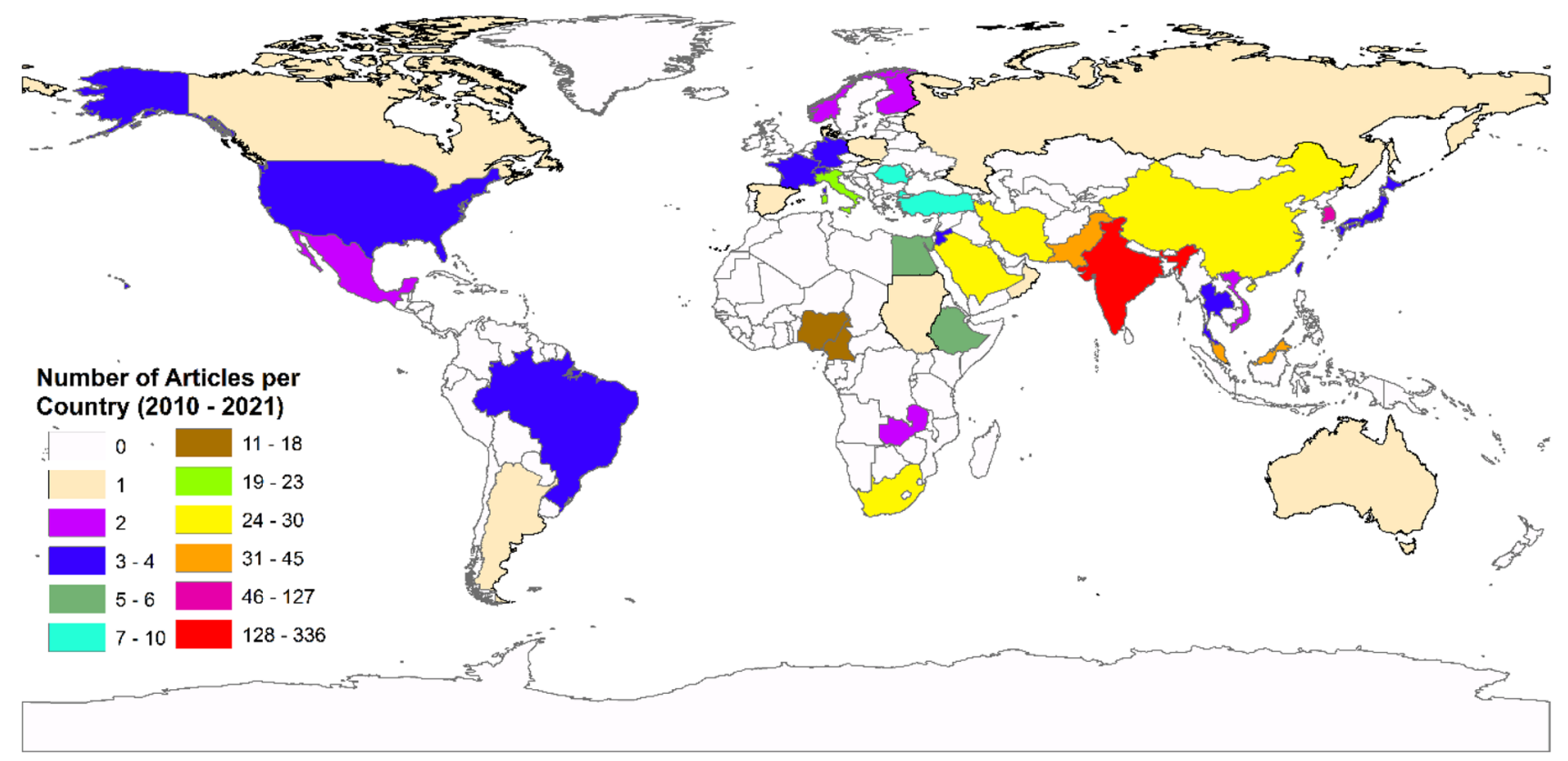

Fig. 10 Country-wise publication of plant-mediated AgNP papers

\section{Limitations of plant-mediated AgNP biosynthesis}

While most of the review articles on plant-mediated biosynthesis of AgNPs foscussed simply on the success of the process, very few articles addressed the potential challenges and shortcomings of this approach. Therefore, in this review, an attempt has been made to discuss the major factors limiting the yield, and operational scalability of AgNP production, like concentration of the plant extracts, the source/type of phytochemicals, the stoichiometric ratios of the reagents and differing optimal experimental conditions. Theses limitations have been broadly categorized below under the following sections: technical limitations, engineering and economical.

\section{Variability in synthesis parameters}

The precursor concentration, the stoichiometric ratio of precursor to plant extract, reaction incubation time, reaction temperature and $\mathrm{pH}$ are all key factors that can affect the morphological characteristics (size and shape) of AgNP as well as yield. Khalil et al. (2014) reported the formation of smaller particles $(8-15 \mathrm{~nm})$ was favoured by a higher ratio of the bio-extract: precursor $\left(5 \mathrm{~mL}\right.$ in a $10 \mathrm{~mL} \mathrm{Ag}^{+}$ solution), and particle size increased (up to $30 \pm 6 \mathrm{~nm}$ ) with a decreasing ratio of the bio-extract: precursor solution $\left(1 \mathrm{~mL}\right.$ in a $10 \mathrm{~mL} \mathrm{Ag}^{+}$solution), whereas Johnson and Prabu (2015) reported increasing phytochemical concentration increased AgNP size. However, Shaikh et al. (2020) reported increasing AgNP size with decreasing precursor $\left(\mathrm{AgNO}_{3}\right)$ concentration due to the occurrence of a narrow SPR band. Suresh et al. (2014) had suggested that during the biosynthesis of AgNP using Delphinium denudatum root extracts the reaction incubation time affected the bio-reduction. In this work, while an initially sharp UV absorption spectra was observed, increasing the incubation time cuased the UV absorption spectra to become wider indicating larger AgNP. Most studies support a positive correlation between AgNP yield and temperature increase (up to an optimum temperature, generally $300 \mathrm{~K})$. Karthik et al. (2017) found that $\mathrm{pH}$ was a most important factor influencing variation in size and shape when using a Camellia japonica leaf extract. Moreover, the literature of Karthik et al. (2017) also suggests that not only do different plant extracts have different $\mathrm{pH}$, but also that even the extracts of different plant parts from the same plant may have different $\mathrm{pH}$, which also affects morphology, shape, and size.

The main limitation of all of these different studies was together the observations tended to be contradictory and no similar trends were observed between disparate studies. Generally, this occurs because to a large extent the results vary significnly depending both on the different plant extracts used and thus the differnces in the presence of various phytochemicals. Another limitation is purity and yield of the final compounds because separation of AgNP from the colloidal phase is challanging. One of the most significant concerns of plant-mediated AgNP synthesis is obtaining high yield. Increasing yield by changing the biosynthesis parameter(s) often leads to the higher-sized AgNP. Moreover, specific

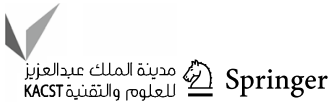


phytochemicals and background chemistry control the size and morphology of AgNP shape and size. Thus, identification of the specific phytochemicals involved in AgNP biosynthesis is required to understand the mechanism. However, the lack of good extract characterization in terms of the common phytochemicals present is a major issue when trying to undserstand relationships between yield, morphology, and plant extract chemicals. Though research has claimed that biosynthesis of AgNP is more environment friendly than either chemical or physical approaches, failed to be prove it due to a significant lack of clear scientific evidence (Mittal et al. 2013). The assertion of environmenmtal friendlieness is based mainly on consideration of how much toxic chemicals are substituted by non-toxic alternatives during biosynthesis or how much energy is saved, and the perceived ecological and economic impacts (Kumar et al. 2020; Kumar and Bhattacharya 2021).

\section{Engineering limitations}

To maintain quality, in terms of uniformity of size and surface composition, which are both essential for assuring enhanced performance, commercial AgNP is synthesized under rigorous standards. However, most biosynthesized AgNP particle's shape and size cannot be well controlled and this often affects phsiochemcial properties like electrical conductivity. Furthermore, most studies indicate that biosynthesized AgNP are polydispersed due to the diversity in the phytochemicals originating from different plant materials. Nouri et al. (2020) reported that the presence of alkene, amide, alcohol, alkaloids, flavonoids, phenol, proteins, saccharides, steroids, saponins, sugar, and tannins in Mentha aquatica leaf extract induced the biosynthesis of spherical AgNP. However, Khoshnamvand et al. (2019) reported formation of spherical, ellipsoidal, and hexagonal AgNP using an Allium ampeloprasum leaf extract, while cubic (size $\sim 68.06 \mathrm{~nm}$ ), flower shaped (size $25 \mathrm{~nm}$ ), hexagonal (size 20-80 nm), rectangular flakes (size 7-24 nm), and truncated triangular shaped (size 10-30 nm) AgNP were biosynthesized when using Andrographis echioides leaf extract (Elangovan et al. 2015), Chrysophyllum oliviforme leaf extract (Anju Varghese et al. 2015), Alpinia officinarum Rhizome extract (Li et al. 2020), Waltheria americana Root extract (Deshi et al. 2016), and Platanus orientalis leaf extract (Al-Thabaiti et al. 2015), respectively.

Some researchers used additional chemicals including cetyltrimethylammonium bromide (CTAB), amphiphilic molecules, surfactants, anionic, cationic and Gemini for shape-controlled AgNP biosynthesis (Al-Thabaiti et al. 2015). However, the particular factor or interaction governing the shapes of the AgNP is still unknown and no scientific evidence or justification was provided to indicate how the parameters or the phytochemicals determined the shape of biosynthesized AgNP.

\section{Economic limitations}

Currently the main economical uncertainlty associated with the biosynthesis approach is that most studies till date have been performed at the laboraoty scale and there is little information on the feasibility of the process on an industrial scale. The large amounts of plant extract required to scale up production, may be an important limiting factor for large scale production. In addition to this, continuous supply of plant materials for extraction of active biomolecules is also uncertain. Johnson and Prabu (2015) reported AgNP synthesis using Commelina benghalensis, Cycascircinalis, Ficus amplissima, and Lippia nodiflora, where the leaf extracts were concentrated by centrifugation at 10,000 rpm for $30 \mathrm{~min}$, exhibiting significant bio-reduction within 15 min with larger spherical sized AgNP formed witha small enhancement in yield. Moreover, to produce large quantities of phytoextractant a significant amount of bimasswaste is generated from the process.

Other important factors to consider include maintaining of high yield and stability, where the chemistry and/or mechanism associated with these factors is not well understood. In addition, the metrics usied in calculating AgNP yield is poorly characterized between different studies (i.e., mass intensity, effective mass yield, and the stoichiometric factor). Likewise, economic feasibility analysis of the biosynthesis of AgNP compared to tradaiotion synthetic methods has not been considered.

However, the identification and separation of phytochemical particularly involved in the bio-reduction is quite impossible but the biosynthesis of continuous, long term industrial scale AgNP may be maintained by using some common native plant species. Plant species having no economic value (i.e., Eichhornia sp., Parthenium hysterophorus) which creates advarce effects due to overgrowth may be a good alternative.

\section{Conclusions}

In recent years, the bioinspired synthesis of AgNP has attracted significant attention, and plant-mediated AgNP synthesis has been the most sought method due to the wide availability of plant sources, environment friendliness of the procedure (without the use of toxic chemicals), high stability of the produced nanoparticles and suitability of the method for large-scale synthesis. This nontoxic size-controlled biosynthesis of AgNP has become inexpensive nanotechnology suitable for a wide range of applications. A wide range of applications like 
biomedical, environmental, agricultural, biosensing, to name a few, have been successful with biosynthesized AgNP particles. Numerous plant species across the globe showed the capability to biosynthesize AgNP particles, as evident from the extensive list summarised in the review due to their presence of a wide array of phytochemicals, though specific biochemical for each function is yet to be elucidated. However, these bio-reduced nanoparticles still pose limitations in large-scale applications, owing to their yield and purity. The limitations and disadvantages have been discussed under engineering, environmental and economic bottlenecks. Finally, the bibliometric analysis of the trend of this plant-mediated AgNP synthesis research revealed that initially, the biosynthesis of AgNP was the main objective, and maximum work on this was done in Asia, with India producing the highest number of scientific articles and citations, while the USA or Europe worked more on applications of the AgNP particles later. Recently instead of using isolated AgNP particles, the technique has shifted to target specific applications with hybrid systems. Finally, it can be concluded that plant-mediated synthesis of silver and other nanoparticles is a lucrative option but requires more research into improving its applicability for a sustainable result.

\section{Research gaps and future recommendations}

In recent years, the biological synthesis of NP (like AgNP) has emerged as an important scientific field. Among the wide number of natural materials, plant extract/biomass has gained significant importance due to the simple one-step inexpensive process, more environment friendly process, and safe to handle chemicals. However, several researchers hypothesized the involvement of specific potential chemical agents/functional groups of the plant species during the synthesis of AgNP. However, considering the diversity of plants and the phytochemicals composition, none of the papers describes the particular phytochemical(s) responsible for the bio-reduction of $\mathrm{Ag}^{+}$(reduce $\mathrm{Ag}^{+}$into $\mathrm{Ag}^{0}$ ) or stabilization rather than the hypothetic bio-reduction mechanism. This area still presents a lacuna in the research of Phyto mediated synthesis of nano particles and need to be addressed. This will help in controlling and achieving the desired size and morphology of the nanoparticles for various applications. This will also help to assess the toxicity of the specific phytochemicals involved in the process on biological organisms once they come in contact in nature.

Supplementary Information The online version contains supplementary material available at https://doi.org/10.1007/s13204-021-02135-5.
Acknowledgements The authors wish to acknowledge the University Grants Commission (UGC), New Delhi, for supporting Wasim Akram Shaikh with doctoral fellowship (F1-17.1/2017-18/MANF-2017-18WES-81391/(SA-III/Website)) and Central Instrumentational Facility (CIF), Birla Insstitute of Technology (BIT) Mesra for characterization.

Author contributions WAS: conceptualization, funding acquisition, writing - original draft; SC: conceptualization, project administration, writing — review and editing; GO: conceptualization, writing-review and editing; RUI: writing-review and editing.

Funding The authors wish to acknowledge the University Grants Commission (UGC), New Delhi, for supporting Wasim Akram Shaikh with doctoral fellowship (F1-17.1/2017-18/MANF-2017-18-WES-81391/ (SA-III/Website)).

Availability of data and material Not applicable.

Code availability Not applicable.

\section{Declarations}

Conflict of interest Not applicable.

Humans and/or animals participants Not applicable.

Ethics approval Not applicable.

Consent to participate Not applicable.

Consent for publication Not applicable.

\section{References}

Abdullah NISB, Ahmad MB, Shameli K (2015) Biosynthesis of silver nanoparticles using Artocarpus elasticus stem bark extract. Chem Cent J. https://doi.org/10.1186/s13065-015-0133-0

Ahmad N, Sharma S, Alam MK et al (2010) Rapid synthesis of silver nanoparticles using dried medicinal plant of basil. Colloids Surfaces B Biointerfaces 81:81-86. https://doi.org/10.1016/j.colsu rfb.2010.06.029

Ahmad N, Sharma S, Singh VN et al (2011) Biosynthesis of silver nanoparticles from Desmodium triflorum: a novel approach towards weed utilization. Biotechnol Res Int 2011:1-8. https://doi.org/ 10.4061/2011/454090

Ahmad A, Wei Y, Syed F et al (2016) Isatis tinctoria mediated synthesis of amphotericin B-bound silver nanoparticles with enhanced photoinduced antileishmanial activity: a novel green approach. J Photochem Photobiol B Biol 161:17-24. https://doi.org/10. 1016/j.jphotobiol.2016.05.003

Ahmed S, Saifullah AM et al (2016) Green synthesis of silver nanoparticles using Azadirachta indica aqueous leaf extract. J Radiat Res Appl Sci 9:1-7. https://doi.org/10.1016/j.jrras.2015.06.006

Ajitha B, Ashok Kumar Reddy Y, Reddy PS (2014a) Biogenic nanoscale silver particles by Tephrosia purpurea leaf extract and their inborn antimicrobial activity. Spectrochim Acta Part A Mol Biomol Spectrosc 121:164-172. https://doi.org/10.1016/j.saa.2013. 10.077

Ajitha B, Ashok Kumar Reddy Y, Sreedhara Reddy P (2014b) Biosynthesis of silver nanoparticles using Plectranthus amboinicus leaf extract and its antimicrobial activity. Spectrochim Acta Part A

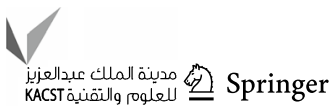


Mol Biomol Spectrosc 128:257-262. https://doi.org/10.1016/j. saa.2014.02.105

Ajitha B, Ashok Kumar Reddy Y, Sreedhara Reddy P (2015) Green synthesis and characterization of silver nanoparticles using Lantana camara leaf extract. Mater Sci Eng C 49:373-381. https:// doi.org/10.1016/j.msec.2015.01.035

Akhtar MS, Panwar J, Yun YS (2013) Biogenic synthesis of metallic nanoparticles by plant extracts. ACS Sustain Chem Eng 1:591602. https://doi.org/10.1021/sc300118u

Ali M, Kim B, Belfield KD et al (2016) Green synthesis and characterization of silver nanoparticles using Artemisia absinthium aqueous extract-a comprehensive study. Mater Sci Eng C 58:359-365. https://doi.org/10.1016/j.msec.2015.08.045

Alishah H, Seyedi SP, Ebrahimipour SY, Esmaeili-Mahani S (2016) a green approach for the synthesis of silver nanoparticles using root extract of Chelidonium majus: characterization and antibacterial evaluation. J Clust Sci 27:421-429. https://doi.org/10. 1007/s10876-016-0968-0

Altemimi A, Lakhssassi N, Baharlouei A et al (2017) Phytochemicals: extraction, isolation, and identification of bioactive compounds from plant extracts. Plants 6:42

Al-Thabaiti SA, Obaid AY, Hussain S, Khan Z (2015) Shape-directing role of cetyltrimethylammonium bromide on the morphology of extracellular synthesis of silver nanoparticles. Arab J Chem 8:538-544. https://doi.org/10.1016/j.arabjc.2014.11.030

Ameen F, Srinivasan P, Selvankumar T et al (2019) Phytosynthesis of silver nanoparticles using Mangifera indica flower extract as bioreductant and their broad-spectrum antibacterial activity. Bioorg Chem 88:102970. https://doi.org/10.1016/j.bioorg.2019. 102970

Anju Varghese R, Anandhi P, Arunadevi R et al (2015) Satin leaf (Chrysophyllum oliviforme) extract mediated green synthesis of silver nanoparticles: antioxidant and anticancer activities. J Pharm Sci Res 7:266-273

Ashkarran AA (2010) A novel method for synthesis of colloidal silver nanoparticles by arc discharge in liquid. Curr Appl Phys 10:1442-1447. https://doi.org/10.1016/j.cap.2010.05.010

Bagherzade G, Tavakoli MM, Namaei MH (2017) Green synthesis of silver nanoparticles using aqueous extract of saffron (Crocus sati$v u s$ L.) wastages and its antibacterial activity against six bacteria. Asian Pac J Trop Biomed 7:227-233. https://doi.org/10.1016/j. apjtb.2016.12.014

Balwe SG, Shinde VV, Rokade AA et al (2017) Green synthesis and characterization of silver nanoparticles (Ag NPs) from extract of plant Radix Puerariae: an efficient and recyclable catalyst for the construction of pyrimido[1,2-b]indazole derivatives under solvent-free conditions. Catal Commun 99:121-126. https://doi. org/10.1016/j.catcom.2017.06.006

Beg M, Maji A, Mandal AK et al (2017) Green synthesis of silver nanoparticles using Pongamia pinnata seed: characterization, antibacterial property, and spectroscopic investigation of interaction with human serum albumin. J Mol Recognit. https://doi. org/10.1002/jmr.2565

Betina V (1966) Identification of antibiotics in crude materials. Antimicrob Agents Chemother 6:637-643. https://doi.org/10.1128/ AAC.6.5.637

Bhakya S, Muthukrishnan S, Sukumaran M, Muthukumar M (2016) Biogenic synthesis of silver nanoparticles and their antioxidant and antibacterial activity. Appl Nanosci 6:755-766. https://doi. org/10.1007/s13204-015-0473-z

Bindhu MR, Umadevi M (2014) Silver and gold nanoparticles for sensor and antibacterial applications. Spectrochim Acta Part A Mol Biomol Spectrosc 128:37-45. https://doi.org/10.1016/j.saa.2014. 02.119

Bogireddy NKR, Kiran Kumar HA, Mandal BK (2016) Biofabricated silver nanoparticles as green catalyst in the degradation of different textile dyes. J Environ Chem Eng 4:56-64. https://doi. org/10.1016/j.jece.2015.11.004

Bonnia NN, Kamaruddin MS, Nawawi MH et al (2016) Green biosynthesis of silver nanoparticles using 'polygonum hydropiper' and study its catalytic degradation of methylene blue. Procedia Chem 19:594-602. https://doi.org/10.1016/j.proche.2016.03.058

Bose D, Chatterjee S (2016) Biogenic synthesis of silver nanoparticles using guava (Psidium guajava) leaf extract and its antibacterial activity against $P$ seudomonas aeruginosa. Appl Nanosci 6:895901. https://doi.org/10.1007/s13204-015-0496-5

Burdușel AC, Gherasim O, Grumezescu AM et al (2018) Biomedical applications of silver nanoparticles: an up-to-date overview. Nanomaterials 8:681

Christenhusz MJM, Byng JW (2016) The number of known plants species in the world and its annual increase. Phytotaxa 261:201-217. https://doi.org/10.11646/phytotaxa.261.3.1

Darmanin T, Nativo P, Gilliland D et al (2012) Microwave-assisted synthesis of silver nanoprisms/nanoplates using a "modified polyol process." Colloids Surfaces A Physicochem Eng Asp 395:145151. https://doi.org/10.1016/j.colsurfa.2011.12.020

de Aragão AP, de Oliveira TM, Quelemes PV et al (2019) Green synthesis of silver nanoparticles using the seaweed Gracilaria birdiae and their antibacterial activity. Arab J Chem 12:4182-4188. https://doi.org/10.1016/j.arabjc.2016.04.014

Deshi JJ, Barminas JT, Onwuka JC et al (2016) Antimicrobial efficacy of biosynthesized silver nanoparticles from different solvent extracts of Waltheria Americana root. J Anal Sci Technol. https:// doi.org/10.1186/s40543-016-0104-7

Dhand V, Soumya L, Bharadwaj S et al (2016) Green synthesis of silver nanoparticles using Coffea arabica seed extract and its antibacterial activity. Mater Sci Eng C 58:36-43. https://doi.org/ 10.1016/j.msec.2015.08.018

Dhayalan M, Denison MIJ, Anitha Jegadeeshwari L et al (2017) In vitro antioxidant, antimicrobial, cytotoxic potential of gold and silver nanoparticles prepared using Embelia ribes. Nat Prod Res 31:465-468. https://doi.org/10.1080/14786419.2016.11664 99

Dong C, Cao C, Zhang X et al (2017) Wolfberry fruit (Lycium barbarum) extract mediated novel route for the green synthesis of silver nanoparticles. Optik (stuttg) 130:162-170. https://doi.org/ 10.1016/j.ijleo.2016.11.010

Dwivedi AD, Gopal K (2010) Biosynthesis of silver and gold nanoparticles using Chenopodium album leaf extract. Colloids Surfaces A Physicochem Eng Asp 369:27-33. https://doi.org/10.1016/j. colsurfa.2010.07.020

Ebrahimzadeh MA, Naghizadeh A, Amiri O et al (2020) Green and facile synthesis of Ag nanoparticles using Crataegus pentagyna fruit extract (CP-AgNPs) for organic pollution dyes degradation and antibacterial application. Bioorg Chem 94:103425. https:// doi.org/10.1016/j.bioorg.2019.103425

Edhari BA, Mashreghi M, Makhdoumi A, Darroudi M (2021) Antibacterial and antibiofilm efficacy of Ag NPs, Ni NPs and Al2O3 NPs singly and in combination against multidrug-resistant Klebsiella pneumoniae isolates. J Trace Elem Med Biol 68:126840. https:// doi.org/10.1016/j.jtemb.2021.126840

Edison TJI, Sethuraman MG (2012) Instant green synthesis of silver nanoparticles using Terminalia chebula fruit extract and evaluation of their catalytic activity on reduction of methylene blue. Process Biochem 47:1351-1357. https://doi.org/10.1016/j.procb io.2012.04.025

Edison TNJI, Atchudan R, Lee YR (2016a) Optical sensor for dissolved ammonia through the green synthesis of silver nanoparticles by fruit extract of Terminalia chebula. J Clust Sci 27:683-690. https://doi.org/10.1007/s10876-016-0972-4

Edison TNJI, Lee YR, Sethuraman MG (2016b) Green synthesis of silver nanoparticles using Terminalia cuneata and its catalytic 
action in reduction of direct yellow-12 dye. Spectrochim Acta Part A Mol Biomol Spectrosc 161:122-129. https://doi.org/10. 1016/j.saa.2016.02.044

Elangovan K, Elumalai D, Anupriya S et al (2015) Phyto mediated biogenic synthesis of silver nanoparticles using leaf extract of Andrographis echioides and its bio-efficacy on anticancer and antibacterial activities. J Photochem Photobiol B Biol 151:118124. https://doi.org/10.1016/j.jphotobiol.2015.05.015

Fatimah I (2016) Green synthesis of silver nanoparticles using extract of Parkia speciosa Hassk pods assisted by microwave irradiation. J Adv Res 7:961-969. https://doi.org/10.1016/j.jare.2016.10.002

Feng QL, Wu J, Chen GQ et al (2000) A mechanistic study of the antibacterial effect of silver ions on Escherichia coli and Staphylococcus aureus. J Biomed Mater Res 52:662-668. https://doi. org/10.1002/1097-4636(20001215)52:4\%3c662::AID-JBM10\% 3e3.0.CO;2-3

Ganapathy Selvam G, Sivakumar K (2015) Phycosynthesis of silver nanoparticles and photocatalytic degradation of methyl orange dye using silver (Ag) nanoparticles synthesized from Hypnea musciformis (Wulfen) J.V. Lamouroux. Appl Nanosci 5:617-622. https://doi.org/10.1007/s13204-014-0356-8

Ghazal S, Akbari A, Hosseini HA et al (2020) Biosynthesis of silverdoped nickel oxide nanoparticles and evaluation of their photocatalytic and cytotoxicity properties. Appl Phys A 126:480. https://doi.org/10.1007/s00339-020-03664-6

Goyal RN, Oyama M, Bachheti N, Singh SP (2009) Fullerene C60 modified gold electrode and nanogold modified indium tin oxide electrode for prednisolone determination. Bioelectrochemistry 74:272-277. https://doi.org/10.1016/j.bioelechem.2008.10.001

Gujrati M, Malamas A, Shin T et al (2014) Multifunctional cationic lipid-based nanoparticles facilitate endosomal escape and reduction-triggered cytosolic siRNA release. Mol Pharm 11:27342744. https://doi.org/10.1021/mp400787s

Gul S, Ismail M, Khan MI et al (2016) Novel synthesis of silver nanoparticles using melon aqueous extract and evaluation of their feeding deterrent activity against housefly Musca domestica. Asian Pacific J Trop Dis 6:311-316. https://doi.org/10.1016/ S2222-1808(15)61036-2

Gupta N, Upadhyaya CP, Singh A et al (2018) Applications of silver nanoparticles in plant protection. Nanotechnol Life Sci. https:// doi.org/10.1007/978-3-319-91161-8_9

Hamedi S, Shojaosadati SA (2019) Rapid and green synthesis of silver nanoparticles using Diospyros lotus extract: evaluation of their biological and catalytic activities. Polyhedron 171:172-180. https://doi.org/10.1016/j.poly.2019.07.010

Hamedi S, Shojaosadati SA, Mohammadi A (2017) Evaluation of the catalytic, antibacterial and anti-biofilm activities of the Convolvulus arvensis extract functionalized silver nanoparticles. J Photochem Photobiol B Biol 167:36-44. https://doi.org/10.1016/j. jphotobiol.2016.12.025

Hatchett DW, White HS (1996) Electrochemistry of sulfur adlayers on the low-index faces of silver. J Phys Chem 100:9854-9859. https://doi.org/10.1021/jp953757z

Hemmati S, Rashtiani A, Zangeneh MM et al (2019) Green synthesis and characterization of silver nanoparticles using Fritillaria flower extract and their antibacterial activity against some human pathogens. Polyhedron 158:8-14. https://doi.org/10.1016/j.poly. 2018.10.049

Hisatomi T, Kubota J, Domen K (2014) Recent advances in semiconductors for photocatalytic and photoelectrochemical water splitting. Chem Soc Rev 43:7520-7535. https://doi.org/10.1039/ c3 $\operatorname{cs} 60378 \mathrm{~d}$

Hutchison JE (2008) Greener nanoscience: a proactive approach to advancing applications and reducing implications of nanotechnology. ACS Nano 2:395-402. https://doi.org/10.1021/nn800 $131 \mathrm{j}$
Ibrahim HMM (2015) Green synthesis and characterization of silver nanoparticles using banana peel extract and their antimicrobial activity against representative microorganisms. J Radiat Res Appl Sci 8:265-275. https://doi.org/10.1016/j.jrras.2015.01.007

Iravani S, Zolfaghari B (2013) Green synthesis of silver nanoparticles using Pinus eldarica bark extract. Biomed Res Int 2013:639725. https://doi.org/10.1155/2013/639725

Jagtap UB, Bapat VA (2013) Green synthesis of silver nanoparticles using Artocarpus heterophyllus Lam. seed extract and its antibacterial activity. Ind Crops Prod 46:132-137. https://doi.org/10. 1016/j.indcrop.2013.01.019

Jamkhande PG, Ghule NW, Bamer AH, Kalaskar MG (2019) Metal nanoparticles synthesis: an overview on methods of preparation, advantages and disadvantages, and applications. J Drug Deliv Sci Technol 53:101174. https://doi.org/10.1016/j.jddst.2019.101174

Jha AK, Prasad K (2010) Green synthesis of silver nanoparticles using cycas leaf. Int J Green Nanotechnol Phys Chem 1:P110-P117. https://doi.org/10.1080/19430871003684572

Johnson I, Prabu HJ (2015) Green synthesis and characterization of silver nanoparticles by leaf extracts of Cycas circinalis, Ficus amplissima, Commelina benghalensis and Lippia nodiflora. Int Nano Lett 5:43-51. https://doi.org/10.1007/s40089-014-0136-1

Joppa LN, Roberts DL, Myers N, Pimm SL (2011) Biodiversity hotspots House most undiscovered plant species. Proc Natl Acad Sci USA 108:13171-13176. https://doi.org/10.1073/pnas.11093 89108

Joseph S, Mathew B (2015) Microwave assisted facile green synthesis of silver and gold nanocatalysts using the leaf extract of Aerva lanata. Spectrochim Acta Part A Mol Biomol Spectrosc 136:1371-1379. https://doi.org/10.1016/j.saa.2014.10.023

Jyoti K, Singh A (2016) Green synthesis of nanostructured silver particles and their catalytic application in dye degradation. J Genet Eng Biotechnol 14:311-317. https://doi.org/10.1016/j.jgeb.2016. 09.005

Jyoti K, Baunthiyal M, Singh A (2016) Characterization of silver nanoparticles synthesized using Urtica dioica Linn. leaves and their synergistic effects with antibiotics. J Radiat Res Appl Sci 9:217-227. https://doi.org/10.1016/j.jrras.2015.10.002

Karthik R, Govindasamy M, Chen SM et al (2017) Biosynthesis of silver nanoparticles by using Camellia japonica leaf extract for the electrocatalytic reduction of nitrobenzene and photocatalytic degradation of Eosin-Y. J Photochem Photobiol B Biol 170:164172. https://doi.org/10.1016/j.jphotobiol.2017.03.018

Karunakaran G, Jagathambal M, Gusev A et al (2016) Allamanda cathartica flower's aqueous extract-mediated green synthesis of silver nanoparticles with excellent antioxidant and antibacterial potential for biomedical application. MRS Commun 6:41-46. https://doi.org/10.1557/mrc.2016.2

Kesharwani J, Yoon KY, Hwang J, Rai M (2009) Phytofabrication of silver nanoparticles by leaf extract of Datura metel: hypothetical mechanism involved in synthesis. J Bionanoscience 3:39-44. https://doi.org/10.1166/jbns.2009.1008

Khalil MMH, Ismail EH, El-Baghdady KZ, Mohamed D (2014) Green synthesis of silver nanoparticles using olive leaf extract and its antibacterial activity. Arab J Chem 7:1131-1139. https://doi.org/ 10.1016/j.arabjc.2013.04.007

Khan AU, Yuan Q, Wei Y et al (2016a) Ultra-efficient photocatalytic deprivation of methylene blue and biological activities of biogenic silver nanoparticles. J Photochem Photobiol B Biol 159:49-58. https://doi.org/10.1016/j.jphotobiol.2016.03.017

Khan ZUH, Khan A, Shah A et al (2016b) Photocatalytic, antimicrobial activities of biogenic silver nanoparticles and electrochemical degradation of water soluble dyes at glassy carbon/silver modified past electrode using buffer solution. J Photochem Photobiol B Biol 156:100-107. https://doi.org/10.1016/j.jphotobiol.2016. 01.016

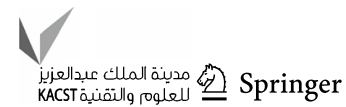


Khan ZUH, Khan A, Shah A et al (2016c) Enhanced photocatalytic and electrocatalytic applications of green synthesized silver nanoparticles. J Mol Liq 220:248-257. https://doi.org/10.1016/j.molliq. 2016.04.082

Khandan Nasab N, Sabouri Z, Ghazal S, Darroudi M (2020) Greenbased synthesis of mixed-phase silver nanoparticles as an effective photocatalyst and investigation of their antibacterial properties. J Mol Struct 1203:127411. https://doi.org/10.1016/j.molst ruc.2019.127411

Khodadadi B, Bordbar M, Nasrollahzadeh M (2017) Achillea millefolium L. extract mediated green synthesis of waste peach kernel shell supported silver nanoparticles: application of the nanoparticles for catalytic reduction of a variety of dyes in water. $\mathbf{J}$ Colloid Interface Sci 493:85-93. https://doi.org/10.1016/j.jcis. 2017.01.012

Khoshnamvand M, Huo C, Liu J (2019) Silver nanoparticles synthesized using Allium ampeloprasum L. leaf extract: Characterization and performance in catalytic reduction of 4-nitrophenol and antioxidant activity. J Mol Struct 1175:90-96. https://doi.org/10. 1016/j.molstruc.2018.07.089

Kirubaharan CJ, Kalpana D, Lee YS et al (2012) Biomediated silver nanoparticles for the highly selective copper(II) ion sensor applications. Ind Eng Chem Res 51:7441-7446. https://doi.org/ 10.1021/ie3003232

Kolya H, Maiti P, Pandey A, Tripathy T (2015) Green synthesis of silver nanoparticles with antimicrobial and azo dye (Congo red) degradation properties using Amaranthus gangeticus Linn leaf extract. J Anal Sci Technol. https://doi.org/10.1186/ s40543-015-0074-1

Kumar A, Bhattacharya T (2021) Biochar: a sustainable solution. Environ Dev Sustain 23:6642-6680. https://doi.org/10.1007/ s10668-020-00970-0

Kumar B, Angulo Y, Smita K et al (2016) Capuli cherry-mediated green synthesis of silver nanoparticles under white solar and blue LED light. Particuology 24:123-128. https://doi.org/10.1016/j. partic.2015.05.005

Kumar B, Smita K, Cumbal L, Debut A (2017) Green synthesis of silver nanoparticles using Andean blackberry fruit extract. Saudi J Biol Sci 24:45-50. https://doi.org/10.1016/j.sjbs.2015.09.006

Kumar A, Bhattacharya T, Mozammil Hasnain SM et al (2020) Applications of biomass-derived materials for energy production, conversion, and storage. Mater Sci Energy Technol 3:905-920. https://doi.org/10.1016/j.mset.2020.10.012

Kumar A, Bhattacharya T, Shaikh WA et al (2021a) Performance evaluation of crop residue and kitchen waste-derived biochar for eco-efficient removal of arsenic from soils of the Indo-Gangetic plain: a step towards sustainable pollution management. Environ Res 200:111758. https://doi.org/10.1016/j.envres.2021.111758

Kumar A, Nagar S, Anand S (2021b) Nanotechnology for sustainable crop production: recent development and strategies. Advances in science, technology and innovation. Springer, Cham, pp 31-47

Larguinho M, Baptista PV (2012) Gold and silver nanoparticles for clinical diagnostics - from genomics to proteomics. J Proteom 75:2811-2823. https://doi.org/10.1016/j.jprot.2011.11.007

Li JF, Liu YC, Chokkalingam M et al (2020) Phytosynthesis of silver nanoparticles using rhizome extract of Alpinia officinarum and their photocatalytic removal of dye under UV and visible light irradiation. Optik (stuttg) 208:164521. https://doi.org/10.1016/j. ijleo.2020.164521

Lim PY, Liu RS, She PL et al (2006) Synthesis of Ag nanospheres particles in ethylene glycol by electrochemical-assisted polyol process. Chem Phys Lett 420:304-308. https://doi.org/10.1016/j. cplett.2005.12.075

Malini S, Vignesh Kumar S, Hariharan R et al (2020) Antibacterial, photocatalytic and biosorption activity of chitosan nanocapsules embedded with Prosopis juliflora leaf extract synthesized silver nanoparticles. Mater Today Proc 21:828-832. https://doi.org/10. 1016/j.matpr.2019.07.587

Mariselvam R, Ranjitsingh AJA, Usha Raja Nanthini A et al (2014) Green synthesis of silver nanoparticles from the extract of the inflorescence of Cocos nucifera (Family: Arecaceae) for enhanced antibacterial activity. Spectrochim Acta Part A Mol Biomol Spectrosc 129:537-541. https://doi.org/10.1016/j.saa. 2014.03.066

Mavaei M, Chahardoli A, Shokoohinia Y et al (2020) One-step synthesized silver nanoparticles using isoimperatorin: evaluation of photocatalytic, and electrochemical activities. Sci Rep. https:// doi.org/10.1038/s41598-020-58697-x

Mittal AK, Chisti Y, Banerjee UC (2013) Synthesis of metallic nanoparticles using plant extracts. Biotechnol Adv 31:346-356. https://doi.org/10.1016/j.biotechadv.2013.01.003

Mohammadi S, Pourseyedi S, Amini A (2016) Green synthesis of silver nanoparticles with a long lasting stability using colloidal solution of cowpea seeds (Vigna sp. L). J Environ Chem Eng 4:2023-2032. https://doi.org/10.1016/j.jece.2016.03.026

Mohanty AS, Jena BS (2017) Innate catalytic and free radical scavenging activities of silver nanoparticles synthesized using Dillenia indica bark extract. J Colloid Interface Sci 496:513-521. https:// doi.org/10.1016/j.jcis.2017.02.045

Moldovan B, David L, Achim M et al (2016) A green approach to phytomediated synthesis of silver nanoparticles using Sambucus nigra $\mathrm{L}$. fruits extract and their antioxidant activity. $\mathrm{J}$ Mol Liq 221:271-278. https://doi.org/10.1016/j.molliq.2016.06.003

Mondal A, Hajra A, Shaikh W et al (2019) Synthesis of silver nanoparticle with Colocasia esculenta (L.) stem and its larvicidal activity against Culex quinquefasciatus and Chironomus sp. Asian Pac J Trop Biomed 9:510-517. https://doi.org/10.4103/2221-1691. 271724

Mondal A, Chowdhury S, Mondal NK et al (2021) Insecticidal and fungicidal performance of bio-fabricated silver and gold nanoparticles. Int J Environ Sci Technol. https://doi.org/10.1007/ s13762-021-03181-w

Muthu K, Priya S (2017) Green synthesis, characterization and catalytic activity of silver nanoparticles using Cassia auriculata flower extract separated fraction. Spectrochim Acta Part A Mol Biomol Spectrosc 179:66-72. https://doi.org/10.1016/j.saa.2017. 02.024

Nayak D, Pradhan S, Ashe S et al (2015) Biologically synthesised silver nanoparticles from three diverse family of plant extracts and their anticancer activity against epidermoid A431 carcinoma. J Colloid Interface Sci 457:329-338. https://doi.org/10.1016/j. jcis.2015.07.012

Nayak D, Ashe S, Rauta PR et al (2016) Bark extract mediated green synthesis of silver nanoparticles: evaluation of antimicrobial activity and antiproliferative response against osteosarcoma. Mater Sci Eng C 58:44-52. https://doi.org/10.1016/j.msec.2015. 08.022

Nouri A, Tavakkoli Yaraki M, Lajevardi A et al (2020) Ultrasonicassisted green synthesis of silver nanoparticles using Mentha aquatica leaf extract for enhanced antibacterial properties and catalytic activity. Colloids Interface Sci Commun 35:100252. https://doi.org/10.1016/j.colcom.2020.100252

Ocsoy I, Temiz M, Celik C et al (2017) A green approach for formation of silver nanoparticles on magnetic graphene oxide and highly effective antimicrobial activity and reusability. J Mol Liq 227:147-152. https://doi.org/10.1016/j.molliq.2016.12.015

Okafor F, Janen A, Kukhtareva T et al (2013) Green synthesis of silver nanoparticles, their characterization, application and antibacterial activity. Int J Environ Res Public Health 10:5221-5238. https://doi.org/10.3390/ijerph10105221

Ondari Nyakundi E, Padmanabhan MN (2015) Green chemistry focus on optimization of silver nanoparticles using response surface 
methodology (RSM) and mosquitocidal activity: Anopheles stephensi (Diptera: Culicidae). Spectrochim Acta Part A Mol Biomol Spectrosc 149:978-984. https://doi.org/10.1016/j.saa. 2015.04.057

Parlinska-Wojtan M, Kus-Liskiewicz M, Depciuch J, Sadik O (2016) Green synthesis and antibacterial effects of aqueous colloidal solutions of silver nanoparticles using camomile terpenoids as a combined reducing and capping agent. Bioprocess Biosyst Eng 39:1213-1223. https://doi.org/10.1007/s00449-016-1599-4

Patil RS, Kokate MR, Kolekar SS (2012) Bioinspired synthesis of highly stabilized silver nanoparticles using Ocimum tenuiflorum leaf extract and their antibacterial activity. Spectrochim Acta Part A Mol Biomol Spectrosc 91:234-238. https://doi.org/10.1016/j. saa.2012.02.009

Pattanayak S, Mollick MMR, Maity D et al (2017) Butea monosperma bark extract mediated green synthesis of silver nanoparticles: Characterization and biomedical applications Butea monosperma bark extract mediated green synthesis of silver nanoparticles. J Saudi Chem Soc 21:673-684. https://doi.org/10.1016/j.jscs. 2015.11.004

Philip D, Unni C, Aromal SA, Vidhu VK (2011) Murraya Koenigii leaf-assisted rapid green synthesis of silver and gold nanoparticles. Spectrochim Acta Part A Mol Biomol Spectrosc 78:899904. https://doi.org/10.1016/j.saa.2010.12.060

Prabhu S, Poulose EK (2012) Silver nanoparticles: mechanism of antimicrobial action, synthesis, medical applications, and toxicity effects. Int Nano Lett. https://doi.org/10.1186/2228-5326-2-32

Pradhan N, Pal A, Pal T (2002) Silver nanoparticle catalyzed reduction of aromatic nitro compounds. Colloids Surfaces A Physicochem Eng Asp 196:247-257. https://doi.org/10.1016/S0927-7757(01) 01040-8

Qing T, Mahmood M, Zheng Y et al (2018) A genomic characterization of the influence of silver nanoparticles on bone differentiation in MC3T3-E1 cells. J Appl Toxicol 38:172-179. https://doi.org/ 10.1002/jat. 3528

Qiu G, Gai Z, Tao Y et al (2020) Dual-functional plasmonic photothermal biosensors for highly accurate severe acute respiratory syndrome coronavirus 2 detection. ACS Nano 14:5268-5277. https://doi.org/10.1021/acsnano.0c02439

Rai M, Bonde S, Yadav A et al (2021) Nanotechnology as a shield against covid-19: current advancement and limitations. Viruses. https://doi.org/10.3390/v13071224

Raina S, Roy A, Bharadvaja N (2020) Degradation of dyes using biologically synthesized silver and copper nanoparticles. Environ Nanotechnol Monit Manag 13:100278. https://doi.org/10.1016/j. enmm.2019.100278

Raja S, Ramesh V, Thivaharan V (2017) Green biosynthesis of silver nanoparticles using Calliandra haematocephala leaf extract, their antibacterial activity and hydrogen peroxide sensing capability. Arab J Chem 10:253-261. https://doi.org/10.1016/j.arabjc. 2015.06.023

Rajakumar G, Abdul Rahuman A (2011) Larvicidal activity of synthesized silver nanoparticles using Eclipta prostrata leaf extract against filariasis and malaria vectors. Acta Trop 118:196-203. https://doi.org/10.1016/j.actatropica.2011.03.003

Rajakumar G, Gomathi T, Thiruvengadam M et al (2017) Evaluation of anti-cholinesterase, antibacterial and cytotoxic activities of green synthesized silver nanoparticles using from Millettia pinnata flower extract. Microb Pathog 103:123-128. https://doi.org/ 10.1016/j.micpath.2016.12.019

Rajan A, Vilas V, Philip D (2015) Catalytic and antioxidant properties of biogenic silver nanoparticles synthesized using Areca catechu nut. J Mol Liq 207:231-236. https://doi.org/10.1016/j. molliq.2015.03.023

Rajasekharreddy P, Rani PU, Sreedhar B (2010) Qualitative assessment of silver and gold nanoparticle synthesis in various plants: a photobiological approach. J Nanoparticle Res 12:1711-1721. https://doi.org/10.1007/s11051-010-9894-5

Rajkuberan C, Prabukumar S, Sathishkumar G et al (2017) Facile synthesis of silver nanoparticles using Euphorbia antiquorum L. latex extract and evaluation of their biomedical perspectives as anticancer agents. J Saudi Chem Soc 21:911-919. https://doi.org/ 10.1016/j.jscs.2016.01.002

Rao NH, Lakshmidevi N, Pammi SVN et al (2016) Green synthesis of silver nanoparticles using methanolic root extracts of Diospyros paniculata and their antimicrobial activities. Mater Sci Eng C 62:553-557. https://doi.org/10.1016/j.msec.2016.01.072

Rashid S, Azeem M, Khan SA et al (2019) Characterization and synergistic antibacterial potential of green synthesized silver nanoparticles using aqueous root extracts of important medicinal plants of Pakistan. Colloids Surfaces B Biointerfaces 179:317-325. https://doi.org/10.1016/j.colsurfb.2019.04.016

Ravichandran V, Vasanthi S, Shalini S et al (2019) Green synthesis, characterization, antibacterial, antioxidant and photocatalytic activity of Parkia speciosa leaves extract mediated silver nanoparticles. Results Phys 15:102565. https://doi.org/10.1016/j.rinp. 2019.102565

Remita S, Fontaine P, Lacaze E et al (2007) X-ray radiolysis induced formation of silver nano-particles: a SAXS and UV-visible absorption spectroscopy study. Nucl Instruments Methods Phys Res Sect B Beam Interact Mater Atoms 263:436-440. https://doi. org/10.1016/j.nimb.2007.06.032

Roy K, Sarkar CK, Ghosh CK (2015) Photocatalytic activity of biogenic silver nanoparticles synthesized using potato (Solanum tuberosum) infusion. Spectrochim Acta Part A Mol Biomol Spectrosc 146:286-291. https://doi.org/10.1016/j.saa.2015.02.058

Saha J, Begum A, Mukherjee A, Kumar S (2017) A novel green synthesis of silver nanoparticles and their catalytic action in reduction of methylene blue dye. Sustain Environ Res 27:245-250. https:// doi.org/10.1016/j.serj.2017.04.003

Sankaranarayanan A, Munivel G, Karunakaran G et al (2017) Green synthesis of silver nanoparticles using Arachis hypogaea (Ground Nut) root extract for antibacterial and clinical applications. J Clust Sci 28:995-1008. https://doi.org/10.1007/ s10876-016-1084-x

Saravanakumar K, Muthuraj V, Vadivel S (2016) Constructing novel $\mathrm{Ag}$ nanoparticles anchored on $\mathrm{MnO} 2$ nanowires as an efficient visible light driven photocatalyst. RSC Adv 6:61357-61366. https://doi.org/10.1039/c6ra10444d

Sasikala A, Linga Rao M, Savithramma N, Prasad TNVKV (2015) Synthesis of silver nanoparticles from stem bark of Cochlospermum religiosum (L.) Alston: an important medicinal plant and evaluation of their antimicrobial efficacy. Appl Nanosci 5:827835. https://doi.org/10.1007/s13204-014-0380-8

Sathishkumar M, Sneha K, Won SW et al (2009) Cinnamon zeylanicum bark extract and powder mediated green synthesis of nanocrystalline silver particles and its bactericidal activity. Colloids Surfaces B Biointerfaces 73:332-338. https://doi.org/10.1016/j. colsurfb.2009.06.005

Shaikh WA, Chakraborty S, Ul Islam R (2018) UV-assisted photocatalytic degradation of anionic dye (Congo red) using biosynthesized silver nanoparticles: a green catalysis. Desalin Water Treat 130:232-242. https://doi.org/10.5004/dwt.2018.23004

Shaikh WA, Chakraborty S, Islam RU (2020) Photocatalytic degradation of rhodamine B under UV irradiation using Shorea robusta leaf extract-mediated bio-synthesized silver nanoparticles. Int J Environ Sci Technol 17:2059-2072. https://doi.org/10.1007/ s13762-019-02473-6

Shaikh WA, Islam RU, Chakraborty S (2021) Stable silver nanoparticle doped mesoporous biochar-based nanocomposite for efficient removal of toxic dyes. J Environ Chem Eng 9:104982. https:// doi.org/10.1016/j.jece.2020.104982 
Shamaila S, Sajjad AKL, Rymaul NA et al (2016) Advancements in nanoparticle fabrication by hazard free eco-friendly green routes. Appl Mater Today 5:150-199. https://doi.org/10.1016/j.apmt. 2016.09.009

Sigamoney M, Shaik S, Govender P et al (2016) African leafy vegetables as bio-factories for silver nanoparticles: a case study on Amaranthus dubius C Mart. Ex Thell S Afr J Bot 103:230-240. https://doi.org/10.1016/j.sajb.2015.08.022

Singh J, Dhaliwal AS (2020) Plasmon-induced photocatalytic degradation of methylene blue dye using biosynthesized silver nanoparticles as photocatalyst. Environ Technol (united Kingdom) 41:1520-1534. https://doi.org/10.1080/09593330.2018.1540663

Singh AK, Tiwari R, Kumar V et al (2017) Photo-induced biosynthesis of silver nanoparticles from aqueous extract of Dunaliella salina and their anticancer potential. J Photochem Photobiol B Biol 166:202-211. https://doi.org/10.1016/j.jphotobiol.2016.11.020

Sinha T, Ahmaruzzaman M, Bhattacharjee A (2014) A simple approach for the synthesis of silver nanoparticles and their application as a catalyst for the photodegradation of methyl violet $6 \mathrm{~B}$ dye under solar irradiation. J Environ Chem Eng 2:2269-2279. https://doi. org/10.1016/j.jece.2014.10.001

Sreekanth TVM, Ravikumar S, Lee YR (2016) Good use of fruit wastes: eco-friendly synthesis of silver nanoparticles, characterization, BSA protein binding studies. J Mol Recognit 29:253-259. https://doi.org/10.1002/jmr.2525

Stoimenov PK, Klinger RL, Marchin GL, Klabunde KJ (2002) Metal oxide nanoparticles as bactericidal agents. Langmuir 18:66796686. https://doi.org/10.1021/la0202374

Sumi Maria B, Devadiga A, Shetty Kodialbail V, Saidutta MB (2015) Synthesis of silver nanoparticles using medicinal Zizyphus xylopyrus bark extract. Appl Nanosci 5:755-762. https://doi. org/10.1007/s13204-014-0372-8

Suresh G, Gunasekar PH, Kokila D et al (2014) Green synthesis of silver nanoparticles using Delphinium denudatum root extract exhibits antibacterial and mosquito larvicidal activities. Spectrochim Acta Part A Mol Biomol Spectrosc 127:61-66. https:// doi.org/10.1016/j.saa.2014.02.030

Swarnavalli GCJ, Dinakaran S, Raman N et al (2017) Bio inspired synthesis of monodispersed silver nano particles using Sapindus emarginatus pericarp extract—study of antibacterial efficacy. $\mathbf{J}$ Saudi Chem Soc 21:172-179. https://doi.org/10.1016/j.jscs.2015. 03.004

Taheri MM, Abdul Kadir MR, Ahmad Shafiai NK et al (2015) Green synthesis of silver nanoneedles using shallot and apricot tree gum. Trans Nonferrous Met Soc China (english Ed) 25:32863290. https://doi.org/10.1016/S1003-6326(15)63965-6

Tahir K, Nazir S, Li B et al (2015) An efficient photo catalytic activity of green synthesized silver nanoparticles using Salvadora persica stem extract. Sep Purif Technol 150:316-324. https://doi.org/10. 1016/j.seppur.2015.07.012

Talebian S, Wallace GG, Schroeder A et al (2020) Nanotechnologybased disinfectants and sensors for SARS-CoV-2. Nat Nanotechnol 15:618-621. https://doi.org/10.1038/s41565-020-0751-0

Tripathi RM, Kumar N, Shrivastav A et al (2013) Catalytic activity of biogenic silver nanoparticles synthesized by Ficus panda leaf extract. J Mol Catal B Enzym 96:75-80. https://doi.org/10. 1016/j.molcatb.2013.06.018

Trouillas P, Marsal P, Siri D et al (2006) A DFT study of the reactivity of $\mathrm{OH}$ groups in quercetin and taxifolin antioxidants: the specificity of the 3-OH site. Food Chem 97:679-688. https://doi.org/ 10.1016/j.foodchem.2005.05.042

Vaculovicova M, Michalek P, Krizkova S et al (2017) Nanotechnologybased analytical approaches for detection of viruses. Anal Methods 9:2375-2391. https://doi.org/10.1039/c7ay00048k
Valsalam S, Agastian P, Esmail GA et al (2019) Biosynthesis of silver and gold nanoparticles using Musa acuminata colla flower and its pharmaceutical activity against bacteria and anticancer efficacy. J Photochem Photobiol B Biol 201:111670. https://doi.org/10. 1016/j.jphotobiol.2019.111670

Varadavenkatesan T, Selvaraj R, Vinayagam R (2016) Phyto-synthesis of silver nanoparticles from Mussaenda erythrophylla leaf extract and their application in catalytic degradation of methyl orange dye. J Mol Liq 221:1063-1070. https://doi.org/10.1016/j. molliq.2016.06.064

Varadavenkatesan T, Vinayagam R, Selvaraj R (2017) Structural characterization of silver nanoparticles phyto-mediated by a plant waste, seed hull of Vigna mungo and their biological applications. J Mol Struct 1147:629-635. https://doi.org/10.1016/j.molst ruc.2017.07.002

Varadavenkatesan T, Vinayagam R, Selvaraj R (2019) Green synthesis and structural characterization of silver nanoparticles synthesized using the pod extract of Clitoria ternatea and its application towards dye degradation. Mater Today Proc 23:27-29. https:// doi.org/10.1016/j.matpr.2019.04.216

Veerasamy R, Xin TZ, Gunasagaran S et al (2011) Biosynthesis of silver nanoparticles using mangosteen leaf extract and evaluation of their antimicrobial activities. J Saudi Chem Soc 15:113-120. https://doi.org/10.1016/j.jscs.2010.06.004

Velmurugan P, Shim J, Kim HW et al (2020) Bio-functionalization of cotton, silk, and leather using different in-situ silver nanoparticle synthesis modules, and their antibacterial properties. Res Chem Intermed 46:999-1015. https://doi.org/10.1007/ s11164-016-2481-3

Verma A, Mehata MS (2016) Controllable synthesis of silver nanoparticles using Neem leaves and their antimicrobial activity. $\mathbf{J}$ Radiat Res Appl Sci 9:109-115. https://doi.org/10.1016/j.jrras. 2015.11.001

Vidhu VK, Philip D (2014a) Catalytic degradation of organic dyes using biosynthesized silver nanoparticles. Micron 56:54-62. https://doi.org/10.1016/j.micron.2013.10.006

Vidhu VK, Philip D (2014b) Spectroscopic, microscopic and catalytic properties of silver nanoparticles synthesized using Saraca indica flower. Spectrochim Acta Part A Mol Biomol Spectrosc 117:102-108. https://doi.org/10.1016/j.saa.2013.08.015

Vijayaraghavan K, Ashokkumar T (2017) Plant-mediated biosynthesis of metallic nanoparticles: a review of literature, factors affecting synthesis, characterization techniques and applications. J Environ Chem Eng 5:4866-4883. https://doi.org/10.1016/j.jece.2017.09. 026

Yazdi MET, Amiri MS, Hosseini HA et al (2019) Plant-based synthesis of silver nanoparticles in Handelia trichophylla and their biological activities. Bull Mater Sci 42:155. https://doi.org/10. 1007/s12034-019-1855-8

Zhang Y, Cheng X, Zhang Y et al (2013) Biosynthesis of silver nanoparticles at room temperature using aqueous aloe leaf extract and antibacterial properties. Colloids Surfaces A Physicochem Eng Asp 423:63-68. https://doi.org/10.1016/j.colsurfa.2013.01.059

Zhang T, Wang L, Chen Q, Chen C (2014) Cytotoxic potential of silver nanoparticles. Yonsei Med J 55:283-291. https://doi.org/10. 3349/ymj.2014.55.2.283

Publisher's Note Springer Nature remains neutral with regard to jurisdictional claims in published maps and institutional affiliations. 